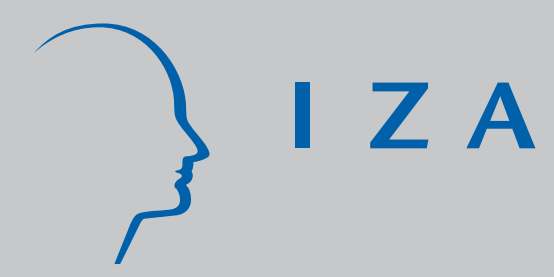

IZADP No. 3364

Explaining the Evolution of Hours Worked and Employment across OECD Countries: An Equilibrium Search Approach

François Langot

Coralia Quintero-Roj as

February 2008 


\title{
Explaining the Evolution of Hours Worked and Employment across OECD Countries: An Equilibrium Search Approach
}

\author{
François Langot \\ PSE-Jourdan, Cepremap, \\ GAINS-TEPP and IZA
}
Coralia Quintero-Rojas
GAINS-TEPP

\author{
Discussion Paper No. 3364 \\ February 2008
}

\author{
IZA \\ P.O. Box 7240 \\ 53072 Bonn \\ Germany \\ Phone: +49-228-3894-0 \\ Fax: +49-228-3894-180 \\ E-mail: iza@iza.org
}

\begin{abstract}
Any opinions expressed here are those of the author(s) and not those of IZA. Research published in this series may include views on policy, but the institute itself takes no institutional policy positions.

The Institute for the Study of Labor (IZA) in Bonn is a local and virtual international research center and a place of communication between science, politics and business. IZA is an independent nonprofit organization supported by Deutsche Post World Net. The center is associated with the University of Bonn and offers a stimulating research environment through its international network, workshops and conferences, data service, project support, research visits and doctoral program. IZA engages in (i) original and internationally competitive research in all fields of labor economics, (ii) development of policy concepts, and (iii) dissemination of research results and concepts to the interested public.
\end{abstract}

IZA Discussion Papers often represent preliminary work and are circulated to encourage discussion. Citation of such a paper should account for its provisional character. A revised version may be available directly from the author. 
IZA Discussion Paper No. 3364

February 2008

\begin{abstract}

\section{Explaining the Evolution of Hours Worked and Employment across OECD Countries: An Equilibrium Search Approach}

Since 1960, the dynamics of the aggregate hours of market work exhibit dramatic differences across industrialized countries. Before 1980, these differences seem to come from the hours worked per employee (the intensive margin). However, since 1980 a notable feature of the data is that the divergence across countries responds to quantitatively important differences along the employment rate (the extensive margin). In this paper we develop an equilibrium matching model where both margins are endogenous. The model is rich enough to account for the behavior of the two margins of the aggregate hours when we include the observed heterogeneity across countries of both the taxes and the labor market institutions such as the unemployment benefits and the bargaining power. Because these findings come from an unified framework, they also give a strong support to the matching models.
\end{abstract}

JEL Classification: E2, J2, J6

Keywords: hours worked, intensive and extensive margins, taxation, labor market institutions, matching model

Corresponding author:

François Langot

ENS, PSE-Jourdan

Cepremap

48 boulevard Jourdan

75014 Paris

France

E-mail: flangot@univ-lemans.fr 


\section{Contents}

1 Stylized Facts $\quad 5$

2 Walrasian growth model $\quad 8$

2.1 When only the intensive margin is endogenous $\ldots \ldots \ldots . \ldots$

2.1 .1 Behaviors . . . . . . . . . . . . . . . . . 8

2.1.2 The equilibrium and parametrization . . . . . . . . . . . 9

2.1 .3 The empirical implications . . . . . . . . . . . . . 10

2.2 When only the extensive margin is endogenous . . . . . . . . . . . . 14

2.2 .1 The Hansen-Rogerson economy . . . . . . . . . . . . . . . . . . . . . . 14

2.2 .2 The equilibrium and parametrization . . . . . . . . . . 15

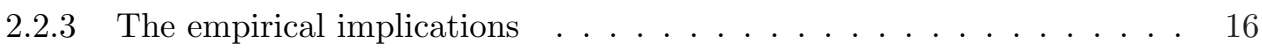

$\begin{array}{llr}3 & \text { Search model with intensive and extensive margins } & 18\end{array}$

3.1 The equilibrium matching model . . . . . . . . . . . . . . . . . 19

3.1.1 Labor market flows . . . . . . . . . . . . . . . . . . . . . . . . 19

3.1 .2 Households . . . . . . . . . . . . . . . . . . . . . . . . . . . . . . . 19

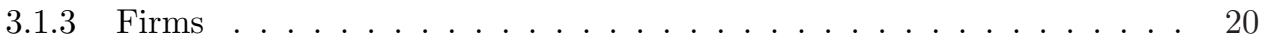

3.1 .4 Nash bargaining . . . . . . . . . . . . . . . . . . . 21

3.1 .5 The Equilibrium . . . . . . . . . . . . . . . . . . . . . 21

3.2 Calibration and data . . . . . . . . . . . . . . . . 24

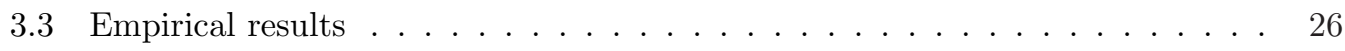

$3.3 .1 \quad$ A world with search costs $\ldots \ldots \ldots \ldots \ldots \ldots$

3.3.2 A world with country-specific institutions . . . . . . . . . . . 28

3.3 .3 A world with country-specific taxation . . . . . . . . . . . 30

3.3.4 A world with country-specific taxation and institutions . . . . . . 31

4 Conclusion $\quad 33$

$\begin{array}{ll}\text { A Data } & 35\end{array}$

B The Hansen-Rorgerson economy by country 36

\section{Introduction}

Aggregate hours of market work exhibit dramatic differences across industrialized countries. What accounts for these differences? In the current literature, there are two candidate approaches allowing to explain these differences. 
A first set of contributions focus on the decline of the average hours worked per employee (the intensive margin) in European countries since 1960. Prescott (2004) studies the role of taxes in accounting for differences in labor supply across time and across countries. He finds that the effective marginal tax rate on labor income explains most of the differences at points of time and the large change in relative (to US) labor supply over time. On this line of research, Rogerson (2006) shows that the aggregate hours worked in Continental European countries such as Belgium, France, Germany and Italy are roughly one third less than in the US. This fact results from a diverging process in the hours worked per employee in each zone: between 1960 and 1980, whereas in Europe we observe a large decrease, in the US this decline is very small; and after 1980, we observe in the two zones a stable number of hours worked per employee. This evolution of the hours worked per employee is strongly correlated to the dynamics of the taxes. Hence, as it is suggested by Prescott (2004), Rogerson (2006) or Ohanian, Raffo, and Rogerson (2006), a theory providing a link between the hours worked per employee and taxes seems to be sufficient to explain why Europeans work less than Americans.

However, since 1980 a notable feature of the data is that differences across countries in aggregate hours are due to quantitatively important differences along the extensive margin. Hence, a second set of contributions (see e.g. Layard and Nickell (1991), Mortensen and Pissarides (1999), Blanchard and Wolfers (2000) or Ljungqvist and Sargent (2007)) considers that the large decrease of the employment rate observed after 1980 in the European countries, is an important factor of the dynamics of total hours. These works show that different labor market institutions lead to different labor market outcomes after a common shock. In these previous papers, there is fairly robust evidence that (i) the level and duration of unemployment benefits and (ii) the union's bargaining power have a significant positive impact on unemployment ${ }^{1}$

To sum up, the main factors explaining the decline in the hours worked per employee differ from those explaining the decline in the employment rate: the taxes for the former, and the labor market institutions, such as the unions' power or the unemployment benefits, for the second. Clearly, all together contribute to the dynamics of the two margins of the total hours.

From a theoretical point of view, the aim of this paper is to provide a theory allowing to account for the impact, of both taxes and labor market institutions, on the two margins

\footnotetext{
${ }^{1}$ There is less consensus on the effects of the employment protection legislation. At the opposite, there is some labor market institutions associated with lower unemployment: highly centralized and/or coordinated wage bargaining systems, as well as some categories of public spending on active labor market programmes. See Daveri and Tabellini (2000) or Bassanini and Duval (2006) who provide a review of recent literature on this topic.
} 
of the aggregate hours worked. To this end, we follow the empirical methodology presented in Ohanian, Raffo, and Rogerson (2006): the quantitative evaluation of the model and the impact of distortions is based on the computation of series for the gap between the marginal cost and the marginal return of labor that is produced using actual data and model restrictions ${ }^{2}$. Furthermore, we extend the theoretical investigation: beyond the usual neoclassical growth model which allows to predict the hours worked per employee, we explore the ability of the Hansen (1985)-Rogerson (1988) model to reproduce the dynamics of the employment rate. Finally, we develop a general equilibrium matching model, close to the one proposed by Andolfatto (1996), Fève and Langot (1996) and Chéron and Langot (2004), allowing to explain the dynamics of both the hours worked per employee and the employment rate. This last model is rich enough to allow the evaluation of the relative contribution of the tax/benefit systems and unions in the explanation of the observed allocation of time.

Our sample consists of six countries: Belgium, Spain, France, Italy, United Kingdom and the United States. Depending on the availability of data, the analysis covers the 1980-2003 or the 1960-2003 period. The main findings are the following. First, the long-run decline in the hours worked per employee is mainly due to the increase of the taxes, as it is suggested by Prescott (2004), Rogerson (2006) and Ohanian, Raffo, and Rogerson (2006). Second, the employment rate is affected by institutional aspects of the labor market, such as the bargaining power and the unemployment benefits, rather than by taxes, conversely to the individual work effort. Finally, this behavior of the two margins of the aggregate hours is well accounted by our search model, when it includes the observed heterogeneity of the tax/benefit systems and the labor market indicators of the wage-setting process across countries. These findings give some support to the two explanations of the European decline in total hours: the important role of taxes through the intensive margin and the large contribution of the labor market institutions through the extensive margin. Because these findings come from an unified framework, they also give a strong support to the matching models.

In the first section of the paper, we present some stylized facts concerning the total hours worked, the contrasted dynamics of the hours worked per employee (the intensive margin) and those relative to the employment rate (the extensive margin). The second section is devoted to explore the implications of two walrasian growth models: in the first one only the intensive margin is endogenous, whereas in the second one, only the extensive margin is endogenous. This extension of the Ohanian, Raffo, and Rogerson (2006)'s work clearly shows that the increase in the divergence between theory and data is explained by two factors: the taxes for the intensive margin, and the labor market institutions for the employment rate. In the third section, we propose a model where both margins are endogenous. Moreover,

\footnotetext{
${ }^{2}$ The closer these gaps are to zero, the better the model accounts for the observed labor behavior.
} 
this framework, by introducing search and wage bargaining, allows to measure the relative contribution of the labor market institutions and taxes. Last section gives the concluding remarks.

\section{$1 \quad$ Stylized Facts}

In this part we establish some facts concerning the allocation of time in the countries of our sample: Belgium, Spain, France, Italy, United Kingdom, United States ${ }^{3}$. To this goal, we decompose the aggregate number of hours between the average hours worked per employee (intensive margin) and the employment rate (extensive margin):

$$
\underbrace{\frac{N h}{A}}_{\text {Total hours }}=\underbrace{h}_{\text {hours }} \times \underbrace{\frac{N}{A}}_{\text {employment }}
$$

where $A$ denotes the active population (i.e. , employed plus unemployed), $h$ the yearly hours worked per employee and $N$ the total civilian employment. As a first overview of the labor behavior, we compute the sample mean of each variable in equation (1) over the 1960 to 2003 period (table 1 ). We observe notable differences in the total hours of work $(N h / A)$. Moreover, countries with similar performances, measured by the aggregate hours, show different work efforts $(h)$ and employment rates $(N / A)$. For instance, the average total hours worked in Spain and France are very close to the total hours worked in the US. However, while in France employees work as much as in the US, in Spain the individual work effort is high enough to compensate its lower employment rate with respect to France and the US.

Since the heterogeneity in the total number of hours worked is driven by the heterogeneity of its components, we estimate their weight in the variance of the mean total hours (last line of table 1). Results enhance the relevance of taking into account both margins: the hours worked per employee and the employment rate have similar weights.

Next, we turn to the the evolution over time of the aggregate hours and its components, displayed in figures 1 to 3 . To avoid scale problems, the total number of hours and the individual effort are displayed on the left hand panel of each figure, and the employment rate on the right hand panel.

Aggregate hours. Most countries experience a sustained decrease in the aggregate hours until the early 80s. The only exception is Spain, where the decline starts around 1970. It is worth to notice that before 1975, the aggregate hours worked in the US are lower than in the European countries.

\footnotetext{
${ }^{3}$ See appendix A for details on the data.
} 
Table 1: Averages over 1960 - 2003

\begin{tabular}{l|ccc}
\hline \hline & $\frac{N h}{A}$ & $h$ & $\frac{N}{A}$ \\
\hline \hline Belgium & 1682 & 1806 & 0.928 \\
Spain & 1756 & 1958 & 0.892 \\
France & 1745 & 1861 & 0.933 \\
Italy & 1598 & 1738 & 0.917 \\
United Kingdom & 1921 & 2033 & 0.943 \\
United States & 1760 & 1868 & 0.941 \\
\hline \hline Variance decomposition & $V[h]$ & $V[N / A]$ & $\operatorname{Cov}(h, N / A)$ \\
\hline & 0.50556 & 0.42814 & 0.066302 \\
\hline \hline
\end{tabular}

To avoid distortions associated to the dependence of the variance to the dimension of the variables, we normalize the hours per employee $h$ as follows: $h^{*}=\frac{h}{h_{\max }}$, where $h_{\max }=14 * 365$; is the maximum number of hours per year to be shared between work and leisure. See appendix A for details on the data.

Figure 1: Belgium and Spain
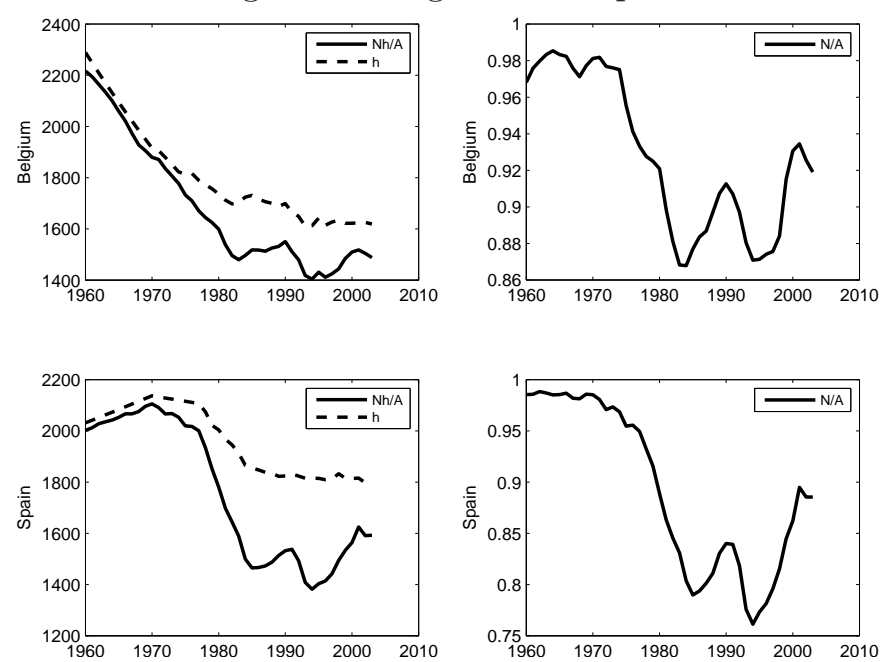
Figure 2: France and Italy
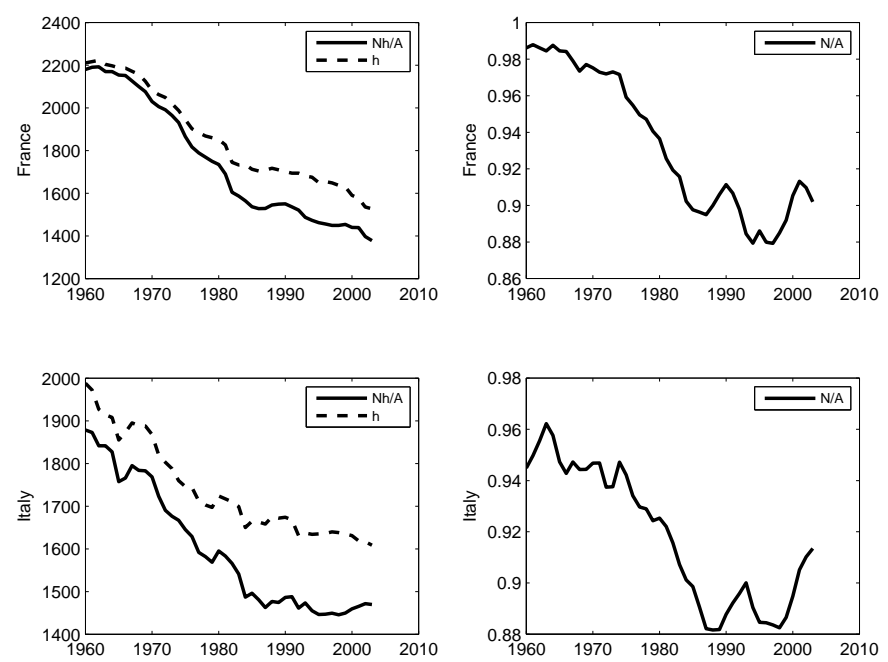

Figure 3: UK and US
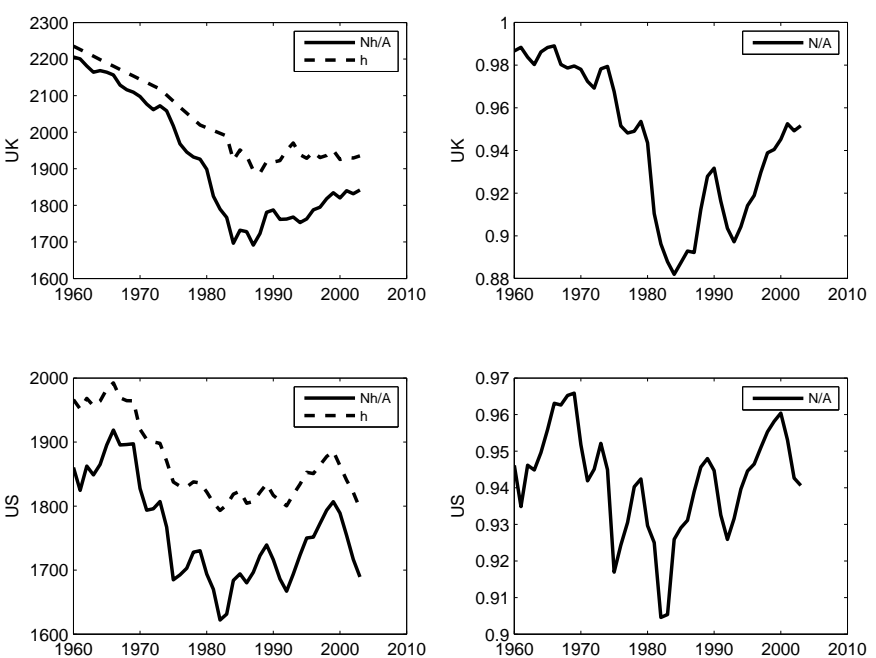
After 1982, the aggregate hours worked remain roughly stable in Belgium and Italy, and still decreasing in France. Conversely, they increase in Spain, the UK, and the US. Finally, even if the UK and the US display a similar evolution, the aggregate hours in the UK still higher than in the US.

Hours per employee. The hours worked per employee exhibit a sustained decline along the whole period in Belgium, France, Italy and the UK. In Spain, the decline starts around 1970. This decline is particularly sharp before 1980. By contrast, in the US the hours per employee decrease until the early 80s and then levels off. But it is still lower than in the UK.

Employment rate. Before 1985, all countries experience a steady decline in the employment rate of roughly $10 \%$. Then there is virtually no trend in Belgium, Spain, France and Italy. Whereas, in the US and the UK, the employment rate (in tendency) increases ever since.

\section{Walrasian growth model}

In this section, we test the ability of two walrasian models to account for the long run dynamics of the labor market in OECD countries. The first model focus on the dynamic of the intensive margin (the number of hours worked per employee), whereas the second only explain the dynamic of the extensive margin (the employment rate).

\subsection{When only the intensive margin is endogenous}

In this first section we propose to analyze the link between the hours worked per employee and the labor market taxes. Similarly to Prescott (2004), Rogerson (2006) and Ohanian, Raffo, and Rogerson (2006), we use the traditional walrasian growth model where the hours worked per employee are divisible: full-employment insures that the employment rate is constat and that all the labor market adjustments are driven by the intensive margin.

\subsubsection{Behaviors}

The economy is populated by a large number of identical households whose measure is normalized to one. Each household consists of a continuum of infinitely-lived agents. At each period there is full employment: $N_{t}=1, \forall t$. The representative household's preferences are

$$
\sum_{t=0}^{\infty} \beta^{t} U\left(C_{t}, 1-h_{t}\right)
$$


where $0<\beta<1$ is the discount factor. $C_{t}$ stands for per capita consumption and $1-h_{t}$ for the leisure time. The contemporaneous utility function is assumed to be increasing and concave in both arguments and it shows conventional separability between consumption and leisure:

$$
U\left(C_{t}, 1-h_{t}\right)=\ln C_{t}+\sigma \ln \left(1-h_{t}\right) \quad \sigma>0
$$

The capital stock $K_{t}$ is rented to firms at net price $\left(r_{t}+\delta\right)$, where $0<\delta<1$ is the depreciation rate of capital. Each household chooses $\left\{C_{t}, h_{t}, K_{t+1} \mid t \geq 0\right\}$ to maximize (2) subject to the budget constraint

$$
\left(1+R_{t}\right) K_{t}+\left(1-\tau_{w, t}\right) w_{t} h_{t}+L_{t}+\pi_{t}-K_{t+1}-\left(1+\tau_{c, t}\right) C_{t} \geq 0 \quad\left(\lambda_{t}\right)
$$

where $R_{t}=\left(1-\tau_{k}\right) r$ is the effective interest rate, $\tau_{k}$ is the capital income tax rate, $\tau_{c}$ is the consumption tax rate, $\tau_{w}$ the labor income tax rate, and $b$ are the unemployment benefits. $L$ is a lump-sum transfer from the government. We assume a balanced budget at each period. $w$ and $\pi$ are the real wage and lump-sum dividends remitted by firms.

Each firm has access to the Cobb-Douglas production technology to produce output. Each producer maximizes the following profit flow:

$$
\pi_{t}=A_{t} K_{t}^{\alpha}\left(h_{t}\right)^{1-\alpha}-\left(1+\tau_{f, t}\right) w_{t} h_{t}-\left(r_{t}+\delta\right) K_{t}
$$

where $0<\alpha<1$ and $\tau_{f}$ stands for the payroll taxes. Then, we have $\max \pi=0$.

\subsubsection{The equilibrium and parametrization}

Let $\lambda_{t}$ be the shadow price of the budget constraint, the optimality conditions of these problems lead to:

$$
\begin{aligned}
\lambda_{t} & =\left(\left(1+\tau_{c, t}\right) C_{t}\right)^{-1} \\
w_{t} & =\frac{\sigma\left(1-h_{t}\right)^{-1}}{\left(1-\tau_{w, t}\right) \lambda_{t}} \\
1 & =\beta\left[\frac{\lambda_{t+1}}{\lambda_{t}}\left(1+\left(1-\tau_{k, t+1}\right)\left(\alpha \frac{Y_{t+1}}{K_{t+1}}-\delta\right)\right)\right] \\
w_{t} & =\frac{(1-\alpha) Y_{t}}{\left(1+\tau_{f, t}\right) h_{t}}
\end{aligned}
$$

Therefore, the labor market equilibrium is then determined by:

$$
\begin{aligned}
(1-\alpha) \frac{Y_{t}}{h_{t}} & =\left\{\frac{\left(1+\tau_{f, t}\right)\left(1+\tau_{c, t}\right)}{1-\tau_{w, t}}\right\} \sigma\left(1-h_{t}\right)^{-1} C_{t} \\
\Leftrightarrow M P H_{t}^{w} & =\left(1+T W_{t}\right) \times M R S(H / C)_{t}
\end{aligned}
$$

where $M P H_{t}^{w}$ and $M R S(H / C)$ denote respectively the marginal product of an hour worked and the marginal rate of substitution between hours worked and consumption. The tax wedge is defined by:

$$
1+T W_{t}=\frac{\left(1+\tau_{f, t}\right)\left(1+\tau_{c, t}\right)}{1-\tau_{w, t}}
$$


Following Ohanian, Raffo, and Rogerson (2006), one can compute the gap between the return and the cost of the marginal hours worked as follows:

$$
M R S(H / C)_{t}=\left(1-\Delta_{t}^{h, w}\right) M P H_{t}^{w} \text { for } T W=0 \Rightarrow \Delta_{t}^{h, w}=1-\frac{M R S(H / C)_{t}}{M P H_{t}^{w}}
$$

In this case, the measure of $\Delta_{t}^{h, w}$ includes the restriction of full employment $\left(N_{t}=1\right)$. Hence, $Y_{t}$ is measured by the aggregate production per capita, $C_{t}$ by the aggregate consumption per capita and $h_{t}$ by the average number of hours worked per employee. Finally, in order to compute the empirical counterpart of $\Delta_{t}^{h, w}$, we choose the same parameters of the structural model than in Ohanian, Raffo, and Rogerson (2006): $\alpha=.4$ and $\sigma=2$.

If the labor supply is evaluated without the tax wedge, i.e. if $T W=0$, we have, under the assumption that the model is able to generate the observed data $M P H_{t}^{w}>M R S(H / C)_{t}$. From the point of view of the econometrician, for a given known set of structural parameters, $\Delta_{t}^{h, w}$ is the residual of the the first order equation estimated with an omitted variable, the tax wedge. If this omitted variable has a trend component, the estimation of $\Delta_{t}^{h, w}$ has also this trend. Hence, the measure of $\Delta_{t}^{h, w}$ gives the impact of the tax wedge on the observed data, under the null assumption that the theory is not rejected. Then, in what follows we interpret $\Delta_{t}^{h, w}$ as the wedge between the neo-classical growth model without taxes and data. In economic terms, this gap provides a measure of the under-utilization of the working time implied by the disincentive effect of taxes. Indeed, when taxes are large, the number of hours supplied decreases for a given wage. Hence, the larger the taxes, the larger is the gap between the labor demand (driven by the marginal productivity) and the labor supply as measured without taxes.

\subsubsection{The empirical implications}

The time series of $\Delta_{t}^{h, w}$ are computed for the six countries of our sample. The cross-country means of the wedges, relative to 1980, are showed in figure 4 (solid line). The first property documented by Ohanian, Raffo, and Rogerson (2006) seems to be verified: the average wedge produced by the model without taxes increases at a fairly steady rate from 1960 to the mid 80 s, when it levels off. ${ }^{4}$

Various factors can explain the labor wedges, including distorting taxation, product market regulation, non-competitive wage setting and labor market regulation. The role of taxes is remarkable from the beginning of the period until the mid 80s. (see figure 5 and table 2).

Then, one may expect that the incorporation of distorting taxation reduces the size of the

\footnotetext{
${ }^{4}$ Given the normalization of the wedge to be zero in all countries in 1980 , it is only the change in the wedge that has any significance. However, we kept this normalization to get series comparable with those of the authors.
} 
Figure 4: Mean wedges - Walrasian model with intensive margin

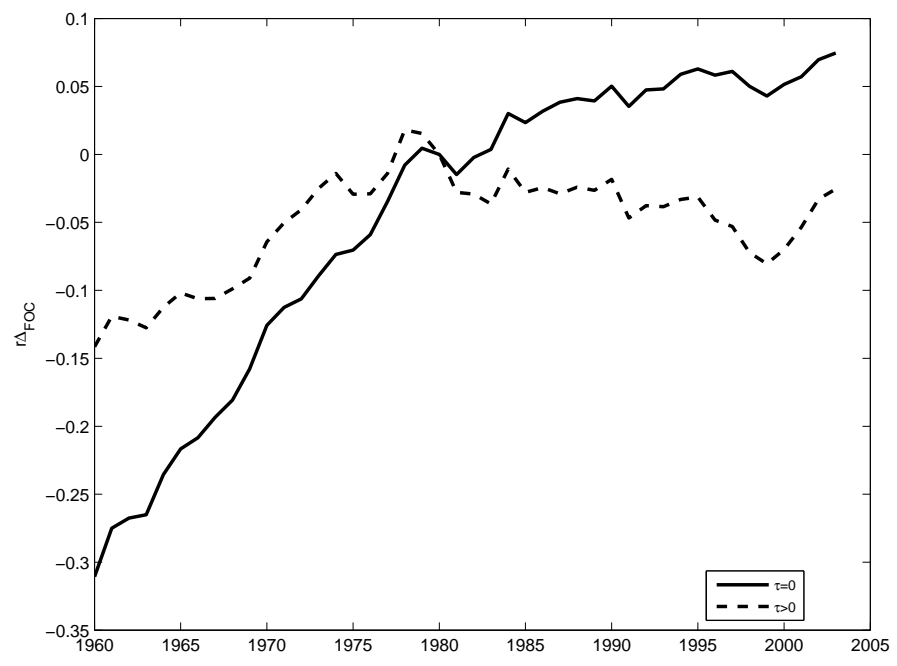

We take 1980 as normalization year. For details on the data see the appendix A.

Figure 5: Hours and Taxes

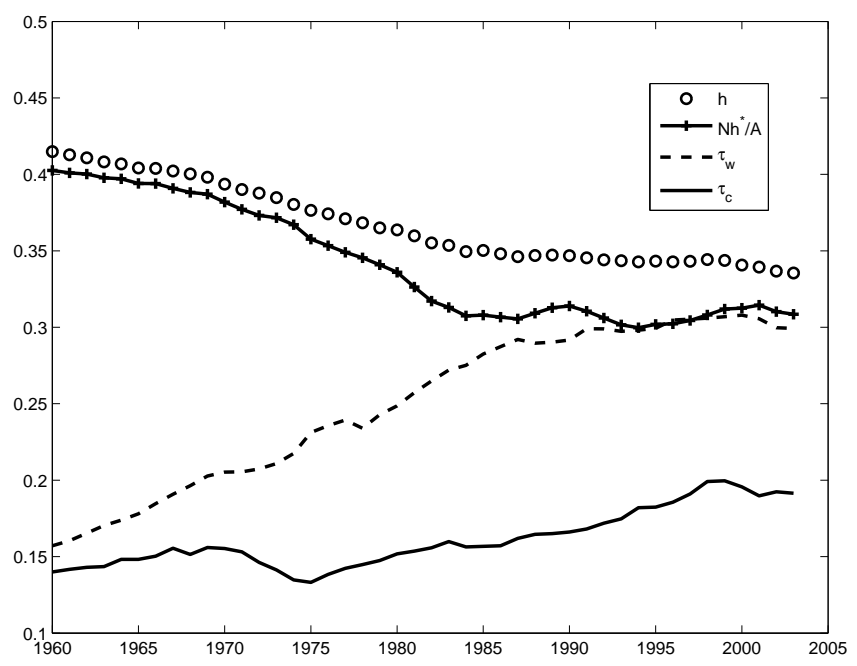

$h^{*}=\frac{h}{h_{\max }}$, where $h_{\max }=14 * 365$ is the maximum number of hours per year to be shared between work and leisure. $\tau_{w}$ and $\tau_{c}$ are respectively the average tax rates on labor income and consumption. For details on the taxes see McDaniel (2007). 
Table 2: Correlations with the labor income taxes

\begin{tabular}{l|ccc}
\hline \hline Absolute & $1960-2003$ & $1960-1980$ & $1980-2003$ \\
\hline \hline Aggregate hours $\left(\frac{N h}{L}\right)$ & -0.981 & -0.970 & -0.558 \\
Hours per employee $(h)$ & -0.991 & -0.982 & -0.885 \\
Employment rate $\left(\frac{N}{A}\right)$ & -0.905 & -0.868 & 0.185 \\
\hline \hline
\end{tabular}

wedge over time and across the countries. With taxes, the wedges are computed as follows:

$\left(1+T W_{t}\right) M R S(H / C)_{t}=\left(1-\Delta_{t}^{h, w}\right) M P H_{t}^{w}$ for $T W>0 \Rightarrow \Delta_{t, T W>0}^{h, w}=1-\left(1+T W_{t}\right) \frac{M R S(H / C)_{t}}{M P H_{t}^{w}}$

The dotted line in figure 4 confirms our intuition: the size of the gap is reduced over time and across countries when we consider distorting taxation.

On the other side, the negative impact of the labor market institutions on the performance of European labor markets after 1980 is well documented. In coherence with the search model developed in section 3, we conduct a simple statistical analysis to assess the impact of two institutional factors other than taxes that are typically thought to influence the labor market equilibrium. The strategy is to perform a panel regression to investigate the importance of taxes, the worker's bargaining power, and the average replacement rate in explaining the evolution in wedges. The specification is:

$$
\ln \left(1-\Delta_{i, t, T W=0}^{h, w}\right)=a_{i}+b \ln \left(T W_{i, t}-1\right)+\gamma \operatorname{Barg}_{i, t}+\beta A R R_{i, t}+\epsilon_{i, t}
$$

where $a_{i}$ is a country-specific fix effect, $\operatorname{Barg}_{i, t}$ is the workers' bargaining power, measured as the average of the union coverage and the union density (see section 3.2), and $A R R_{i, t}$ is the average replacement rate. The results from the regression (table 3) show that taxes have a significant negative impact on the variation in the hours wedge. This result seems to be robust: for all the specifications (regressions (1) to (4)), the tax wedge has a negative significant impact at $5 \%$ level. At the opposite, the labor market institutions (LMI) have not significant impact on this wedge between theory and data. Regression (5) shows that the bargaining power, as the sole explanatory variable, has not significant effect. Finally, regressions (6) and (7) show that the average replacement ratio is correlated with taxes: in countries where taxes are high and follow an increasing path, the unemployment benefit follows this trend. Hence, if we omit taxes as an explanatory variable, the average replacement ratio has a significant negative impact on the dynamics of wedge between theory and data. These results give some support to the view that the increase in taxation is the main explanative factor of the large decrease in the hours worked in the OECD countries. 
Table 3: Regression results for the hours, 1980-2003

\begin{tabular}{|c|c|c|c|c|c|c|c|}
\hline & $\operatorname{Reg}(1)$ & $\operatorname{Reg}(2)$ & $\operatorname{Reg}(3)$ & Reg (4) & $\operatorname{Reg}(5)$ & $\operatorname{Reg}(6)$ & $\operatorname{Reg}(7)$ \\
\hline \multirow[t]{2}{*}{$a_{b e}$} & .2055 & .0370 & .2690 & .0047 & .0348 & .0119 & .3177 \\
\hline & {$[-.0860 ; .4970]$} & {$[.0013 ; .0727]$} & {$[-.0016 ; .5397]$} & {$[-.0503 ; .0597]$} & {$[-.3031 ; .3728]$} & {$[-.0548 ; .0787]$} & {$[-.0332 ; .6686]$} \\
\hline \multirow[t]{2}{*}{$a_{s p}$} & .0773 & .0054 & .1364 & -.0427 & .1367 & .1518 & .3300 \\
\hline & {$[-.1061 ; .2606]$} & {$[-.0162 ; .0271]$} & {$[-.0166 ; .2893]$} & {$[-.1088 ; .0234]$} & {$[-.0576 ; .3310]$} & {$[.0958 ; .2078]$} & {$[.1216 ; .5384]$} \\
\hline \multirow[t]{2}{*}{$a_{f r}$} & .1383 & .0236 & .1829 & .0002 & -.0427 & -.0359 & .1755 \\
\hline & {$[-.0648 ; .3415]$} & {$[-.0160 ; .0632]$} & {$[-.0054 ; .3713]$} & {$[-.0496 ; .0500]$} & {$[-.2741 ; .1887]$} & {$[-.0954 ; .0236]$} & {$[-.0699 ; .4208]$} \\
\hline \multirow[t]{2}{*}{$a_{i t}$} & .1510 & -.0094 & .1834 & -.0100 & -.0115 & -.0904 & .1568 \\
\hline & {$[-.0807 ; .3828]$} & {$[-.0409 ; .0220]$} & {$[-.0418 ; .4086]$} & {$[-.0413 ; .0213]$} & {$[-.2927 ; .2697]$} & {$[-.1201 ;-.0607]$} & {$[-.1233 ; .4370]$} \\
\hline \multirow[t]{2}{*}{$a_{u k}$} & .2237 & .1353 & .2712 & .1032 & .2872 & .2576 & .4376 \\
\hline & {$[.0453 ; .4021]$} & {$[.1115 ; .1592]$} & {$[.1123 ; .4300]$} & {$[.0552 ; .1512]$} & {$[.0854 ; .4890]$} & {$[.2213 ; .2939]$} & {$[.2316 ; .6435]$} \\
\hline \multirow[t]{2}{*}{$a_{u s}$} & .1045 & .0843 & .1387 & .0519 & .2462 & .2484 & .3239 \\
\hline & {$[.0123 ; .1967]$} & {$[.0509 ; .1178]$} & {$[.0676 ; .2099]$} & {$[-.0018 ; .1056]$} & {$[.1607 ; .3317]$} & {$[.2187 ; .2780]$} & {$[.2339 ; .4140]$} \\
\hline \multirow[t]{2}{*}{$\mathrm{TW}$} & -.3571 & -.3209 & -.3254 & -.3627 & & & \\
\hline & {$[-.4455 ;-.2687]$} & {$[-.3909 ;-.2509]$} & {$[-.3951 ;-.2557]$} & {$[-.4511 ;-.2744]$} & & & \\
\hline \multirow[t]{2}{*}{ Barg } & -.2666 & & -.3196 & & -.1921 & & -.4062 \\
\hline & {$[-.6468 ; .1135]$} & & {$[-.6891 ; .0500]$} & & {$[-.6604 ; .2762]$} & & {$[-.8639 ; .0515]$} \\
\hline \multirow[t]{2}{*}{ ARR } & .0949 & & & .1222 & & -.2785 & -.3107 \\
\hline & {$[-.0680 ; .2577]$} & & & {$[-.0365 ; .2808]$} & & {$[-.4305 ;-.1266]$} & {$[-.4658 ;-.1556]$} \\
\hline $\mathrm{N}$ & 144 & 144 & 144 & 144 & 144 & 144 & 144 \\
\hline$R^{2}$ & .9248 & .9222 & .9224 & .9237 & .8764 & .8867 & .8892 \\
\hline
\end{tabular}

Ordinary least squares regression. "TW" is the tax wedge, "Barg" the bargaining power of the workers and "ARR" the average replacement rate. The confidence intervals (in brackets) are at the $95 \%$ level. See details on the data in the appendix A. 
To sum up, the average hours per employee decrease since 1960. Without taxation, the wedge between the first order condition (equation (10)) and the data increases over time. Before the 80 's, this negative correlation between the increasing taxes and the hours per employee is large and then explains the large increase in the wedge $\Delta^{h, w}$. After the 80 's, our empirical results suggest that the dynamics of taxes is still correlated with $\Delta^{h, w}$, whereas it is not correlated with the LMI. Then the long-run decline in the hours worked per employee is mainly due to the increase in the taxes as it is suggested by Prescott (2004), Rogerson (2006) and Ohanian, Raffo, and Rogerson (2006).

\subsection{When only the extensive margin is endogenous}

Given that the employment rate and the average hours worked per employee follow different paths in some countries, it is interesting to explore the explanative role of taxation along the extensive margin. To this end, we compute an employment wedge to the equilibrium condition from the Hansen-Rogerson model. In this type of economy, the number of hours per employee is indivisible, and then, only the extensive margin can fluctuate.

\subsubsection{The Hansen-Rogerson economy}

This configuration corresponds to the indivisible labor proposed by Hansen (1985) and Rogerson (1988). At the beginning of each period, the agent plays an employment lottery. If she wins, with probability $N_{t}$, she works $h$ hours. In the opposite case, with probability $1-N_{t}$, she does not work at all.

The utility function of the representative household is linear with respect to labor and is given by: ${ }^{5}$

$$
U_{t}=\ln C_{t}+N_{t} \sigma \ln (1-h) \Leftrightarrow U_{t}=\hat{\sigma} \ln C_{t}+(1-\hat{\sigma})\left(1-N_{t}\right)
$$

Each household chooses $\left\{C_{t}, N_{t}, K_{t+1} \mid t \geq 0\right\}$ to maximize

$$
\sum_{t=0}^{\infty} \beta^{t} U\left(C_{t}, 1-N_{t}\right)
$$

subject to the budget constraint

$$
\left(1+R_{t}\right) K_{t}+\left(1-\tau_{w, t}\right) w_{t} N_{t}+L_{t}+\pi_{t}-K_{t+1}-\left(1+\tau_{c, t}\right) C_{t} \geq 0 \quad\left(\lambda_{t}\right)
$$

\footnotetext{
${ }^{5}$ The utility function is expressed in a simpler way using the ordinal property of utility functions. The transformation implies:

$$
\frac{1-\hat{\sigma}}{\hat{\sigma}}=\sigma \ln \left(\frac{1}{1-h}\right)
$$
}


On the other side, the representative firm chooses $\left\{K_{t}, N_{t} \mid t \geq 0\right\}$ to maximize the discounted value of the dividend flow:

$$
\max \pi=\max _{K_{t}, N_{t}}\left\{Y_{t}-\left(r_{t}+\delta\right) K_{t}-\left(1+\tau_{f, t}\right) w_{t} N_{t}\right\}
$$

subject to the technology constraint:

$$
Y_{t}=A_{t} K_{t}^{\alpha}\left(N_{t}\right)^{1-\alpha}, \quad 0<\alpha<1
$$

implying that $\max \pi=0$.

\subsubsection{The equilibrium and parametrization}

The optimality conditions of these problems lead to:

$$
\begin{aligned}
\lambda_{t} & =\left(\hat{\sigma}\left(1+\tau_{c, t}\right) C_{t}\right)^{-1} \\
w_{t} & =\frac{1-\hat{\sigma}}{\left(1-\tau_{w, t}\right) \lambda_{t}} \\
1 & =\beta\left[\frac{\lambda_{t+1}}{\lambda_{t}}\left(1+\left(1-\tau_{k, t+1}\right)\left(\alpha \frac{Y_{t+1}}{K_{t+1}}-\delta\right)\right)\right] \\
w_{t} & =\frac{(1-\alpha) Y_{t}}{\left(1+\tau_{f, t}\right) N_{t}}
\end{aligned}
$$

Therefore, the labor market equilibrium is then determined by:

$$
\underbrace{(1-\alpha) \frac{Y_{t}}{N_{t}}}_{M P N_{t}}=\left(1+T W_{t}\right) \underbrace{\left(\frac{1-\hat{\sigma}}{\hat{\sigma}}\right) C_{t}}_{M R S^{H a n s}(N / C)_{t}}
$$

where $M P N_{t}$ and $M R S^{H a n s}(N / C)$ denote respectively the marginal product of an employee who works $h$ hours and the marginal rate of substitution between employment and consumption. Note that, contrary to the previous model, equation (18) shows that, for a given wage, the variations in consumption are orthogonal to those in the employment. In this economy, the gap between the marginal return and the marginal cost of employment is computed as follows:

$$
\begin{aligned}
\left(1+T W_{t}\right) M R S^{\text {Hans }}(N / C)_{t} & =\left(1-\Delta_{t}^{n, \text { Hans }}\right) M P N_{t} \text { for } T W \geq 0 \\
\Rightarrow \Delta_{t}^{n, \text { Hans }} & =1-\left(1+T W_{t}\right) \frac{M R S^{\text {Hans }}(N / C)_{t}}{M P N_{t}}
\end{aligned}
$$

In this case, there is not full employment but the measure of $\Delta_{t}^{n, H a n s}$ includes the restriction that employees work a fixed amount of time. Hence, $Y_{t}$ is measured by the aggregate production per capita, $C_{t}$ by the aggregate consumption per capita, and $N_{t}$ by the total civilian employment.

As in the divisible labor model, we choose the same parameters than in Ohanian, Raffo, and Rogerson (2006), i.e. $\alpha=.4$ and $\sigma=2$. Given that the (normalized) average number of hours worked by employee is equal to $h=0.3563$, we deduce that $\hat{\sigma}=0.5316$. 


\subsubsection{The empirical implications}

Proceeding as before, we compute time series for the six countries of our sample. The crosscountry means of the employment wedges, relative to 1980, are shown in figure 6 . Contrarily than for the average hours worked per employee (previous section), the mean employment wedge, calculated without taxes, display virtually no trend (solid line). This, together with the results from the employment regressions (Table 4), suggests that taxes have a little or a not significant impact on employment. In other words, the correlation between the trend of the taxes and the cross-country means of employment wedges seems less robust. Indeed, when we incorporate taxes, the size of the mean wedge largely increases after the 70s, displaying a period of sharp decrease that is persistent in Europe. This suggest that the explanation of the labor market trend based only on the joint dynamics of hours worked per employee and taxes, as it is proposed in Prescott (2004), Rogerson (2006) or Ohanian, Raffo, and Rogerson (2006), must be completed.

Figure 6: Walrasian model with extensive margin

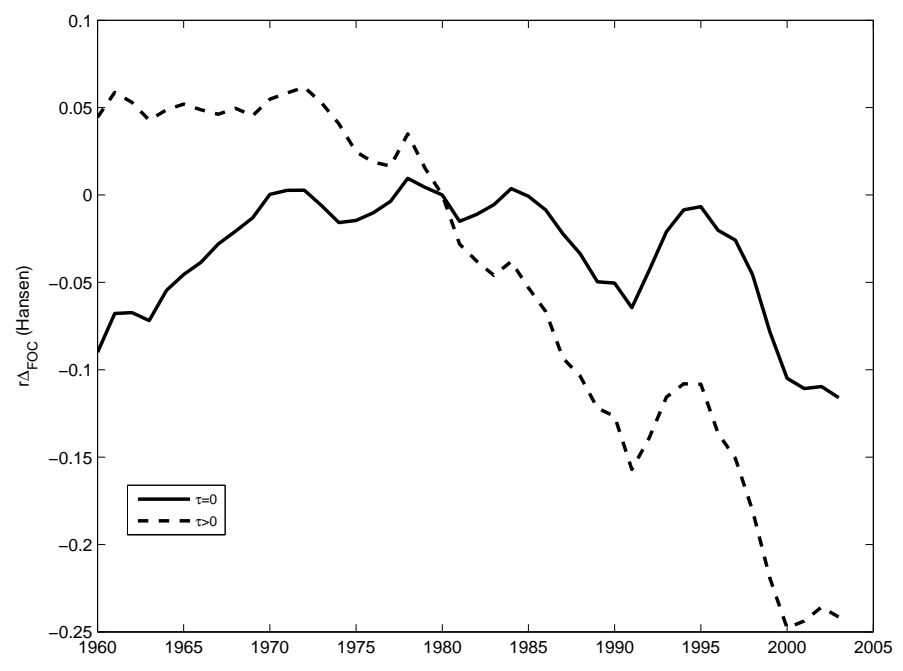

We take 1980 as normalization year. For details on the data see the appendix A.

The large literature on the European unemployment experience underlines that, conversely to the individual work effort, the employment rate is more likely to be affected by the institutional aspects of the labor market rather than by taxes. In order to test the relevance of this hypothesis, we conduct the same simple statistical analysis than for the hours worked per employee. We measure the influence of two institutional factors other than taxes, namely the bargaining power and the unemployment benefits, that are typically thought to influence the employment rate.

As before, the strategy is to perform panel regressions to investigate the importance 
of taxes, the worker's bargaining power, and the average replacement rate in explaining the evolution of employment wedges. Indeed, the average replacement rate is the product between the initial unemployment benefit replacement rate $(R R 1)$ and the duration of the unemployment benefits $(U B D 1)$. Then, we estimate the model:

$$
\ln \left(1-\Delta_{i, t, T W=0}^{n, H a n s}\right)=a_{i}+b \ln \left(T W_{i, t}-1\right)+\gamma B \operatorname{Barg}_{i, t}+\beta R R 1_{i, t}+\delta U B D 1_{i, t}+\epsilon_{i, t}
$$

Results are presented in table 4 . We observe that the effect of taxes is not significant

Table 4: Regression results for the employment, 1980-2003

\begin{tabular}{|c|c|c|c|c|c|c|c|}
\hline & $\operatorname{Reg}(1)$ & $\operatorname{Reg}(2)$ & $\operatorname{Reg}(3)$ & $\operatorname{Reg}(4)$ & $\operatorname{Reg}(5)$ & $\operatorname{Reg}(6)$ & $\operatorname{Reg}(7)$ \\
\hline \multirow[t]{2}{*}{$a_{b e}$} & -0.4583 & -1.2336 & -.7994 & -1.184 & -.7722 & -1.173 & -.5567 \\
\hline & {$[-.8418 ;-.0748]$} & {$[-1.282 ;-1.184]$} & {$[-1.151 ;-.4479]$} & {$[-1.250 ;-1.118]$} & {$[-1.120 ;-.4234]$} & {$[-1.239 ;-1.107]$} & {$[-.9457 ;-.1676]$} \\
\hline \multirow{2}{*}{$a_{s p}$} & -0.7522 & -1.3145 & -1.065 & -1.215 & -1.071 & -1.274 & -.9005 \\
\hline & [-1.008;-.4962] & {$[-1.339 ;-1.289]$} & {$[-1.266 ;-.8638]$} & {$[-1.305 ;-1.125]$} & {$[-1.272 ;-.8700]$} & {$[-1.345 ;-1.202]$} & [-1.143;-.6578] \\
\hline \multirow[t]{2}{*}{$a_{f r}$} & -0.6809 & -1.2328 & -.9380 & -1.183 & -.9084 & -1.162 & -.7313 \\
\hline & [-.9509;-.4108] & {$[-1.286 ;-1.178]$} & {$[-1.180 ;-.6956]$} & {$[-1.252 ;-1.115]$} & {$[-1.145 ;-.6712]$} & {$[-1.228 ;-1.096]$} & {$[-1.007 ;-.4554]$} \\
\hline \multirow[t]{2}{*}{$a_{i t}$} & -0.6528 & -1.2554 & -.8970 & -1.237 & -.8738 & -1.217 & -.7179 \\
\hline & {$[-.9607 ;-.3450]$} & {$[-1.298 ;-1.212]$} & [-1.187;-.6065] & {$[-1.284 ;-1.189]$} & {$[-1.161 ;-.5857]$} & {$[-1.261 ;-1.173]$} & {$[-1.031 ;-.4041]$} \\
\hline \multirow[t]{2}{*}{$a_{u k}$} & -0.4298 & -0.9498 & -.6955 & -.8817 & -.7063 & -.9444 & -.5812 \\
\hline & {$[-.6770 ;-.1825]$} & {$[-.9799 ;-.9196]$} & {$[-.9016 ;-.4895]$} & {$[-.9607 ;-.8028]$} & {$[-.9118 ;-.5008]$} & {$[-.9973 ;-.8915]$} & {$[-.8130 ;-.3495]$} \\
\hline \multirow[t]{2}{*}{$a_{u s}$} & -0.5013 & -0.7875 & -.6838 & -.7154 & -.7049 & -.7894 & -.6307 \\
\hline & [-.6368;-..3659] & {$[-.8312 ;-.7439]$} & {$[-.7774 ;-.5903]$} & {$[-.7962 ;-.6345]$} & {$[-.7912 ;-.6186]$} & {$[-.8305 ;-.7484]$} & {$[-.7372 ;-.5243]$} \\
\hline \multirow[t]{2}{*}{$T W$} & 0.1670 & 0.0559 & .0546 & .1234 & & & \\
\hline & {$[.0540 ; .2801]$} & {$[-.0403 ; .1522]$} & {$[-.0397 ; .1490]$} & {$[.0067 ; .2400]$} & & & \\
\hline \multirow[t]{2}{*}{ Barg } & -0.9605 & & -.6021 & & -.6051 & & -.8116 \\
\hline & {$[-1.461 ;-.4598]$} & & {$[-1.085 ;-.1192]$} & & {$[-1.088 ;-.1217]$} & & {$[-1.316 ;-.3064]$} \\
\hline \multirow[t]{2}{*}{$R R 1$} & -0.1704 & & & -.1033 & & -.0662 & -.1118 \\
\hline & {$[-.2682 ;-.0726]$} & & & {$[-.1995 ;-.0072]$} & & {$[-.1570 ; .0245]$} & {$[-.2039 ;-.0197]$} \\
\hline \multirow[t]{2}{*}{$U B D 1$} & -0.0619 & & & -.0362 & & -.0036 & -.0155 \\
\hline & {$[-.1212 ;-.0026]$} & & & {$[-.0970 ; .0246]$} & & {$[-.0567 ; .0495]$} & {$[-.0673 ; .0363]$} \\
\hline $\mathrm{N}$ & 144 & 144 & 144 & 144 & 144 & 144 & 144 \\
\hline$R^{2}$ & .9329 & .9268 & .9310 & .9275 & .9310 & .9269 & .9320 \\
\hline
\end{tabular}

Ordinary least squares regression. " $T W$ " is the tax wedge, "Barg" the bargaining power of the workers, " $R R 1$ " the initial unemployment benefit replacement rate, and " $U B D 1$ " the unemployment benefit duration (years).

The confidence intervals (in brackets) are at the $95 \%$ level. See details on the data in the appendix A.

when the tax wedge is the only regressor (regression (2)); or when only the bargaining power is included (regression (3)). However, taxes become significant in combination with 
the $R R 1$ and the $U D B 1$ (regressions (1) and (4)). In contrast with the results obtained for individual hours, taxes have a negative effect on the employment wedge (equivalently, a positive effect on $\left.\log \left(1-\Delta_{i, t, T W=0}^{n, \text { Hans }}\right)\right)$ : the observed increase in taxes induces a downward trend in the estimated gap between the theory and the data. Then, as is suggested by figure 6 , the persistent decrease in the employment rate not explained by the walrasian model $a \grave{a} l a$ Hansen-Rogerson is not due to a shift in taxes.

What about the labor market indicators? The results from this set of regressions show that the negative effect of the workers' bargaining power is robust: it remains negative and significant in all regressions. Finally, concerning the unemployment benefits, we notice that the initial replacement rate $(R R 1)$ has a significant negative effect on the employment wedges. This effect seems quite robust, even if, when no other regressor is included (regression (6)), it is significant only at the $20 \%$ level. At the opposite, the impact of the duration of the unemployment benefits $(U B D 1)$ is not robust: in the complete regression (regression (1)), its impact is negative and significant, whereas in the other regressions, it is not significant.

These statistical results support the view that the labor market institution shifts explain the wedge between theory and data when data.

To sum up, the employment rate is decreasing until the early 1980s. Then it remains stable in France and Italy, whereas in the other countries it shows a slight (Belgium and Spain) to moderate increasing trend (US and UK). Without taxation, the wedge between the first order condition and data displays virtually no significant trend. Finally, this wedge is negatively correlated with both the workers' bargaining power and the unemployment benefits, in particular with the initial replacement rate (RR1). Moreover, the tax wedge is not correlated with the gap between the theoretical model and the data $\left(\Delta^{n, \text { Hans }}\right)$.

Since 1980, a notable feature of the data is that differences across countries in aggregate hours are due to quantitatively important differences along the extensive margin and the intensive margin. Then, it seems relevant to analyze the labor market dynamics taking into account these two margins. Moreover, in this alternative quantitative model, the introduction of the labor market institutions is expected to reduce the gap between the marginal cost and the marginal return of labor. This is done in the search economy developed in next section.

\section{Search model with intensive and extensive margins}

In this section we propose a theoretical framework allowing to explain simultaneously the dynamics of the employment and the hours worked per employee. We also need for a theory explaining the impact of the labor market institutions such as the bargaining power and the unemployment benefits. The natural candidate is then the matching model, where both 
employment and hours are endogenous. With this type of model, we are able to quantify the relative importance of taxes and of labor market institutions in the total hours dynamics. More precisely, we expect that our model is able to explain that the dynamics of the hours worked per employee is mainly accounted by the taxes, whereas the employment dynamics is driven by the labor market institutions.

\subsection{The equilibrium matching model}

We present in this section a neo-classical growth model where the labor market equilibrium is determined by a search process and a wage bargaining process. This model is close to the one analyzed by Andolfatto (1996), Fève and Langot (1996) and Chéron and Langot (2004).

\subsubsection{Labor market flows}

Employment is predetermined at each time and changes only gradually as workers separate from jobs, at the exogenous rate $s$, or unemployed agents find jobs, at the hiring rate $M_{t}$. Let $N_{t}$ and $V_{t}$, respectively be the number of workers and the total number of new jobs made available by firms, then employment evolves according to

$$
N_{t+1}=(1-s) N_{t}+M_{t}
$$

with $M_{t}=V_{t}^{\psi}\left(1-N_{t}\right)^{1-\psi}, \quad 0<\psi<1$.

\subsubsection{Households}

The economy is populated by a large number of identical households whose measure is normalized to one. Each household consists of a continuum of infinitely-lived agents. At any period, an agent can engage in only one of two activities: working or searching for a job. Employed agents $(N)$ work $h$ hours, while unemployed $(1-N)$ expend their time searching a job. Unemployed agents are randomly matched with job vacancies. Individual idiosyncratic risks faced by each agent in his job match are smoothed by using employment lotteries. Hence, the representative household's preferences are:

$$
\mathcal{W}\left(\Omega_{0}^{H}\right)=\sum_{t=0}^{\infty} \beta^{t}\left[N_{t} U\left(C_{t}^{n}, 1-h_{t}\right)+\left(1-N_{t}\right) U\left(C_{t}^{u}\right)\right]
$$

where $0<\beta<1$ is the discount factor and $\Omega_{t}^{H}=\left\{K_{t}, N_{t}, \Psi_{t}, w_{t}, h_{t}, b_{t}, \pi_{t}, R_{t}, L_{t}\right\}, \forall t . C_{t}^{n}$ and $C_{t}^{u}$ stand for the consumption of employed and unemployed agents. The contemporaneous utility function is assumed to be increasing and concave in both arguments and it shows conventional separability between consumption and leisure, to know:

$$
U\left(C_{t}^{z}, L_{t}^{z}\right)=\ln C_{t}^{z}+\Gamma_{t}^{z}, \quad z=n, u \text {. }
$$


where $\Gamma_{t}^{n}=\sigma \log \left(1-h_{t}\right)$, with $\sigma>0$, and $\Gamma_{t}^{u}=\Gamma^{u}=0, \forall t$.

A household's employment opportunities evolve as follows:

$$
N_{t+1}=(1-s) N_{t}+\Psi_{t}\left(1-N_{t}\right)
$$

$\Psi \equiv M_{t} /\left(1-N_{t}\right)$ is the rate at which unemployed agents find jobs.

The capital stock $K_{t}$ is rented to firms at net price $\left(r_{t}+\delta\right)$, where $0<\delta<1$ is the depreciation rate of capital. Each household chooses $\left\{C_{t}^{n}, C_{t}^{u}, K_{t+1} \mid t \geq 0\right\}$ to maximize (19) subject to the labor supply constraint (20) and to the budget constraint

$$
\begin{aligned}
K_{t+1}= & -\left(1+\tau_{c, t}\right)\left[N_{t} C_{t}^{n}+\left(1-N_{t}\right) C_{t}^{u}\right] \\
& +\left[1+\left(1-\tau_{k, t}\right) r_{t}\right] K_{t}+\left(1-\tau_{w, t}\right)\left[N_{t} w_{t} h_{t}+\left(1-N_{t}\right) b_{t}\right]+L_{t}+\pi_{t}
\end{aligned}
$$

where $b$ are the unemployment benefits. Then, the first order conditions with respect to consumption and capital are respectively,

$$
\begin{aligned}
& \left(C_{t}^{n}\right)^{-1}=\left(C_{t}^{u}\right)^{-1} \equiv\left(C_{t}\right)^{-1}=\left(1+\tau_{c, t}\right) \lambda_{t} \\
& \beta\left[\left(1+R_{t+1}\right) \lambda_{t+1}\right]=\lambda_{t}
\end{aligned}
$$

\subsubsection{Firms}

There are many identical firms in the economy. Each firm chooses a number $V_{t}$ of job vacancies, produces goods and pays wages and capital services. The unit cost of maintaining an open vacancy is $\omega$. Each firm has access to a Cobb-Douglas production technology to produce output:

$$
Y_{t}=A_{t} K_{t}^{\alpha}\left(N_{t} h_{t}\right)^{1-\alpha}, \quad 0<\alpha<1
$$

Job vacancies are matched at the constant rate $\Phi_{t}=M_{t} / V_{t}$. Hence, a firm's labor employment evolves as

$$
N_{t+1}=(1-s) N_{t}+\Phi_{t} V_{t}
$$

Each firm chooses $\left\{N_{t+1}, K_{t}, V_{t} \mid t \geq 0\right\}$ to maximize the discounted value of the dividend flow, subject to the constraint (24), and to the labor constraint (25):

$$
\begin{aligned}
\mathcal{W}\left(\Omega_{t}^{F}\right) & =\max _{V_{t}, N_{t+1}, K_{t}}\left\{\pi_{t}+\frac{1}{1+R_{t+1}} \mathcal{W}\left(\Omega_{t+1}^{F}\right)\right\} \\
\pi_{t} & =Y_{t}-\left(r_{t}+\delta\right) K_{t}-\omega_{t} V_{t}-\left(1+\tau_{f, t}\right) w_{t} N_{t} h
\end{aligned}
$$

with $\Omega_{t}^{F}=\left\{N_{t}, \Phi_{t}, w_{t}, h_{t}, r_{t}\right\}$ and initial condition $N_{0} . \tau_{f}$ stands for the payroll tax payed by firms. The first order conditions with respect to capital and employment are,

$$
\begin{aligned}
& \alpha \frac{Y_{t}}{K_{t}}=r_{t}+\delta \\
& \frac{\omega_{t}}{\Phi_{t}}=\left[\frac{1}{1+R_{t+1}}\left((1-\alpha) \frac{Y_{t+1}}{N_{t+1}}+\frac{\omega}{\Phi_{t+1}}(1-s)-\left(1+\tau_{f, t+1}\right) w_{t+1} h_{t+1}\right)\right]
\end{aligned}
$$




\subsubsection{Nash bargaining}

Wages and hours are determined via generalized Nash bargaining between individual workers and their firms:

$$
\max _{w_{t}, h_{t}}\left(\lambda_{t} \mathcal{V}_{t}^{F}\right)^{\epsilon_{t}}\left(\mathcal{V}_{t}^{H}\right)^{1-\epsilon_{t}}
$$

with $\mathcal{V}_{t}^{F}=\frac{\partial \mathcal{W}\left(\Omega_{t}^{F}\right)}{\partial N_{t}}$ the marginal value of a match for a firm and $\mathcal{V}_{t}^{H}=\frac{\mathcal{W}\left(\Omega_{t}^{H}\right)}{\partial N_{t}}$ the marginal value for a match for a worker. $\epsilon_{t}$ denotes the firm's bargaining power at date $t$. In coherence with our empirical measure of the worker's bargaining power (left panel of figure 7), this parameter varies over time and across countries.

The solution to this problem are the hours and wage contracts ${ }^{6}$. With an efficient bargaining over hours, the optimal choice of hours worked by employee is closed to the walrasian case. However, the wage contract takes into account the dynamic behavior of taxes and the unemployment benefits.

\subsubsection{The Equilibrium}

Given the vector of taxes, unemployment benefits and bargaining powers $\left\{\tau_{c, t}, \tau_{f, t}, \tau_{w, t}, b_{t}, \epsilon_{t}\right\}$, the general equilibrium is defined by the set of functions $\left\{C_{t}, V_{t}, K_{t+1}, N_{t+1}, w_{t}, h_{t}, L_{t}, M_{t}, Y_{t}\right\}_{t=0}^{\infty}$, solution of the system formed by the optimality conditions, the equation of the employment dynamics and the condition for the equilibrium on the goods markets. Let define the market tightness as $\theta_{t}=V_{t} /\left(1-N_{t}\right)$. Finally, to simplify notation, we define the employment tax: $\tau_{t}^{n} \equiv \frac{1+\tau_{f, t}}{1-\tau_{w, t}}$, and the relative bargaining power: $\chi_{t} \equiv \frac{1-\epsilon_{t}}{\epsilon_{t}}$. Then the system defining the equilibrium is:

$$
\begin{aligned}
& N_{t+1}=(1-s) N_{t}+M_{t} \\
& M_{t}=\theta_{t}^{\psi}\left(1-N_{t}\right) \\
& Y_{t}=K_{t+1}-(1-\delta) K_{t}+C_{t}+\omega V_{t} \\
& L_{t}=\tau_{c, t} C_{t}+\left(\tau_{f, t}+\tau_{w, t}\right) w_{t} h_{t} N_{t}+\tau_{k, t} r_{t} K_{t}-b\left(1-\tau_{w, t}\right)\left(1-N_{t}\right) \\
& Y_{t}=A_{t} K_{t}^{\alpha}\left(h_{t} N_{t}\right)^{1-\alpha} \\
& 1=\beta\left[\frac{\lambda_{t+1}}{\lambda_{t}}\left(1+\left(1-\tau_{k, t+1}\right)\left(\alpha \frac{Y_{t+1}}{K_{t+1}}-\delta\right)\right)\right] \\
& \frac{\omega}{\Phi_{t}}=\beta\left[\frac{\lambda_{t+1}}{\lambda_{t}}\left((1-\alpha) \frac{Y_{t+1}}{N_{t+1}}+(1-s) \frac{\omega}{\Phi_{t+1}}-\left(1+\tau_{f, t+1}\right) w_{t+1} h_{t+1}\right)\right] \\
& \left(\left(1+\tau_{c, t}\right) C_{t}\right)^{-1}=\lambda_{t}
\end{aligned}
$$

${ }^{6}$ See Chéron and Langot (2004) for more details on the wage bargaining process in the neo-classical growth model with matching 


$$
\begin{aligned}
(1-\alpha) \frac{Y_{t}}{N_{t} h_{t}}=\frac{1+\tau_{f, t}}{1-\tau_{w, t}} \frac{\sigma\left(1-h_{t}\right)^{-1}}{\lambda_{t}} & \\
w_{t} h_{t}= & \frac{1-\epsilon_{t}}{1+\tau_{f, t}}\left\{(1-\alpha) \frac{Y_{t}}{N_{t}}+\left[\frac{1-s}{\Phi_{t}}\left(1-\frac{\chi_{t+1}}{\chi_{t}} \frac{\tau_{t}^{n}}{\tau_{t+1}^{n}}\right)+\frac{\chi_{t+1}}{\chi_{t}} \frac{\tau_{t}^{n}}{\tau_{t+1}^{n}} \theta_{t}\right] \omega\right\} \\
& +\frac{\epsilon_{t}}{1-\tau_{w, t}}\left\{\frac{\Gamma^{u}-\Gamma_{t}^{n}}{\lambda_{t}}+\left(1-\tau_{w, t}\right) b_{t}\right\}
\end{aligned}
$$

Finally, the unemployment benefits are computed as the product of the average replacement rate $\left(\rho_{t}\right)$ and the hourly wage: $b_{t}=\rho_{t} w_{t} h_{t}$. The last equation can be rewritten as follows:

$$
\begin{aligned}
\left(1+\tau_{f, t}\right) w_{t} h_{t}= & \frac{1-\epsilon_{t}}{1-\epsilon_{t} \rho_{t}}\left\{(1-\alpha) \frac{Y_{t}}{N_{t}}+\left[\frac{1-s}{\Phi_{t}}\left(1-\frac{\chi_{t+1}}{\chi_{t}} \frac{\tau_{t}^{n}}{\tau_{t+1}^{n}}\right)+\frac{\chi_{t+1}}{\chi_{t}} \frac{\tau_{t}^{n}}{\tau_{t+1}^{n}} \theta_{t}\right] \omega\right\} \\
& +\frac{\epsilon_{t}}{1-\epsilon_{t} \rho_{t}}\left(1+T W_{t}\right)\left(\Gamma^{u}-\Gamma_{t}^{n}\right) C_{t}
\end{aligned}
$$

In the matching model, both the number of employees and the number of hours worked are endogenous. After the wage bargaining process, the right to manage assumption leads the firms to hire a number of workers given a bargained labor cost per employee $((1+$ $\left.\left.\tau_{f, t}\right) w_{t} h_{t}\right)$. Because we assume an efficient bargaining process, the equilibrium number of hours is determined by the same equation than in a walrasian economy (endogenous intensive margin). Then the labor market equilibrium conditions are:

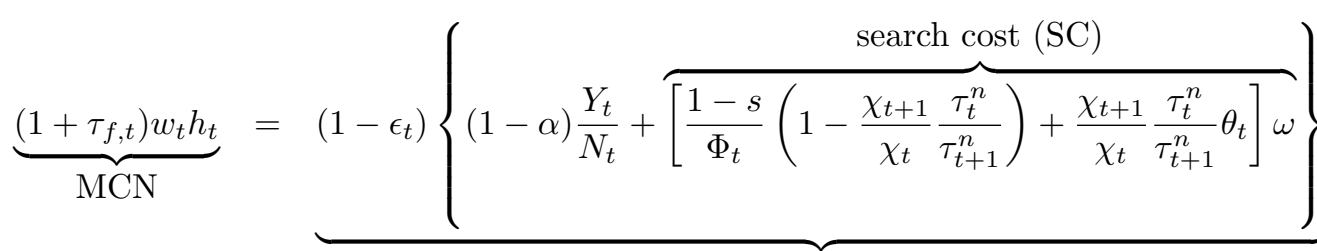

$$
\begin{aligned}
& \text { Bargained surplus (BS) } \\
& +\underbrace{\epsilon_{t}\{\left(1+T W_{t}\right) \overbrace{\left(\Gamma^{u}-\Gamma_{t}^{n}\right) C_{t}}^{\mathrm{MRS}(\mathrm{N} / \mathrm{C})}+\overbrace{\left(1+\tau_{f, t}\right) b_{t}}^{\mathrm{UB}}\}} \\
& \text { Reservation wage (RW) } \\
& \underbrace{\left(1+\tau_{f, t}\right) w_{t} h_{t}}_{\text {MRN }}=\underbrace{(1-\alpha) \frac{Y_{t}}{N_{t}}}_{\text {Instantaneous returns }}+\underbrace{(1-s) \frac{\omega}{\Phi_{t}}-\left\{\frac{\left(1+\tau_{c, t}\right) C_{t}}{\beta\left(1+\tau_{c, t-1}\right) C_{t-1}}\right\} \frac{\omega}{\Phi_{t-1}}}_{\text {Intertemporal returns }} \\
& \underbrace{(1-\alpha) \frac{Y_{t}}{N_{t} h_{t}}}_{\mathrm{MPH}}=\underbrace{\left\{\frac{\left(1+\tau_{f, t}\right)\left(1+\tau_{c, t}\right)}{1-\tau_{w, t}}\right\}}_{1+\mathrm{TW}} \underbrace{\sigma\left(1-h_{t}\right)^{-1} C_{t}}_{\mathrm{MRS}(\mathrm{H} / \mathrm{C})}
\end{aligned}
$$

where $M R N$ denotes the marginal return of an employee and $M C N$ her marginal cost. Similarly, $M R S(N / C)$ denotes the marginal rate of substitution between employment and consumption whereas $M P H$ stands for the marginal product of an hour worked. The previ- 
ous system can be rewritten as:

$$
\begin{aligned}
M R N_{t} & =M C N_{t} \\
M P H_{t} & =\left(1+T W_{t}\right) \times M R S(H / C)_{t}
\end{aligned}
$$

One can remark that the $M C N$ has now two components: the bargained surplus and the reservation wage. Whereas the reservation wage is only affected by the tax/benefit system (tax wedge and unemployment benefits), the bargained surplus is also affected by the labor market frictions through the search cost.

Without taxes and without labor market institutions, i.e. $T W=1-\epsilon=U B=0$, the marginal cost of employment $M C N$ is given by the marginal rate of substitution between employment and consumption $M R S(N / C)$, as in the Hansen-Rogerson economy. Relatively to this walrasian model, the labor market institutions lead to an increase in the $M C N$, through the introduction of both an additional value of leisure (the unemployment benefits $U B>0)$ and a bargained surplus $(1-\epsilon>0)$. Hence, the shift across time of the labor market institutions can explain the dynamics of the employment by decreasing the wedge between the data and the theory. Finally, the increase in the tax wedge $T W$ raises also the marginal cost of employment through the reservation wage. Via this last channel, one can also expect to reduce the gap between data and theory.

Following Ohanian, Raffo and Rogerson (2006), we compute the gap between the return and the cost of the marginal employee as follows:

$$
M C N_{t}=\left(1-\Delta_{t}^{n}\right) M R N_{t} \text { for } T W \geq 0, \quad U B \geq 0 \Rightarrow \Delta_{t}^{n}=1-\frac{M C N_{t}}{M R N_{t}}
$$

Relatively to the Hansen-Rogerson's economy, the matching model leads to new evaluations of both the marginal return of employment $(M R N)$ and the marginal cost of employment $(M C N)$. The smaller the labor market frictions, the smaller is the gap between the HansenRogerson economy and our matching model.

The condition allowing to generate the number of hours worked in the non-walrasian economy is the same than in the walrasian one, except that in the previous case the employment rate is not restricted to be equal to one. This expression does not introduce any labor market friction because we assume an efficient bargaining process over the hours worked. Then we have:

$\left(1+T W_{t}\right) M R S(H / C)_{t}=\left(1-\Delta_{t}^{h}\right) M P H_{t}$ for $T W \geq 0, U B \geq 0 \Rightarrow \Delta_{t}^{h}=1-\left(1+T W_{t}\right) \frac{M R S(H / C)_{t}}{M P H_{t}}$ Contrary to the walrasian case, we do not impose $N_{t}=1$ (full-employment). The measure of $\Delta_{t}^{h}$ is computed using the aggregate production per capita $Y_{t}$, the aggregate consumption per capita $C_{t}$, the number of hours worked by employee $h_{t}$ and the employment rate $N_{t}$. 


\subsection{Calibration and data}

The aim of the empirical part is to measure the contribution of both the labor market indicators (LMI) and the taxes specific of each country. Taxes and LMI were not constant over the last two decades (see figure 7 and figure 9 ). Then, the dynamics of the gap between the marginal cost of employment and its marginal return is affected by changes in either the LMI and the taxes. In order to measure the impact of the tax/benefit system we construct the different hours and employment wedges under several configurations, using the data described in appendix A.

These measures are evaluated using the following parametrization of the structural parameters. We choose $\alpha=0.4$ and $\sigma=2$ as in (Ohanian, Raffo, and Rogerson 2006). The discount parameter is such that $\beta=0.985$. The elasticity of the matching function with respect to vacancies is equal to $\psi=0.6$ (Blanchard and Diamond 1992). We assume a ratio of aggregate recruiting expenditures to output $\left(\omega_{t} V_{t} / Y_{t}\right)$ equal 1\% (Andolfatto 1996). We set $\omega$ equal to the mean over time and countries. Finally, in order to make an easy comparison of the model with and without unemployment, we assume that an unemployed worker enjoys all her leisure time, which means that the search activity has no disutility cost.

The labor market indicators give the dynamics of the bargaining power of workers and the unemployment benefits (the replacement ratio) in each country. We have two statistical indicators which allow us to measure the bargaining power of the employee during the wage bargaining process: the union coverage and the union density. These two indicators are not directly the bargaining power, but are closely linked to it: a large union coverage or a high union density imply that the probability for the employee to be alone during the bargaining process is very low. Hence, the bargaining power is higher in an economy where the firm does not have a monopsony power. We choose to evaluate $1-\epsilon$ by the average of the union coverage and the union density. The dynamics of the LMI are represented in figure 7.

We also take into account the heterogeneity in the separation rate, but this parameter is constant over the time in order to be consistent with our theoretical framework. We calibrate the job destruction rates in order to reproduce the average unemployment duration for the 1985-1994 period estimated by Blanchard and Portugal (2001) (see appendix A). The average unemployment durations and the corresponding destruction rates are summarized in table 5, whereas the evolution of the expected unemployment duration across countries is displayed in figure 8. Notice that in Spain and Italy the unemployment duration shows a large peak (144 months for Spain and 208 for Italy) that corresponds to the economic crisis experienced in the early $90 \mathrm{~s}$.

Finally, figure 9 shows the dynamics in each country of the several taxes that define our tax wedge $(\mathrm{TW})$ : the payroll tax $\left(\tau_{f}\right)$, the tax on labor income $\left(\tau_{w}\right)$ and the tax on 
Figure 7: Bargaining power and replacement rate
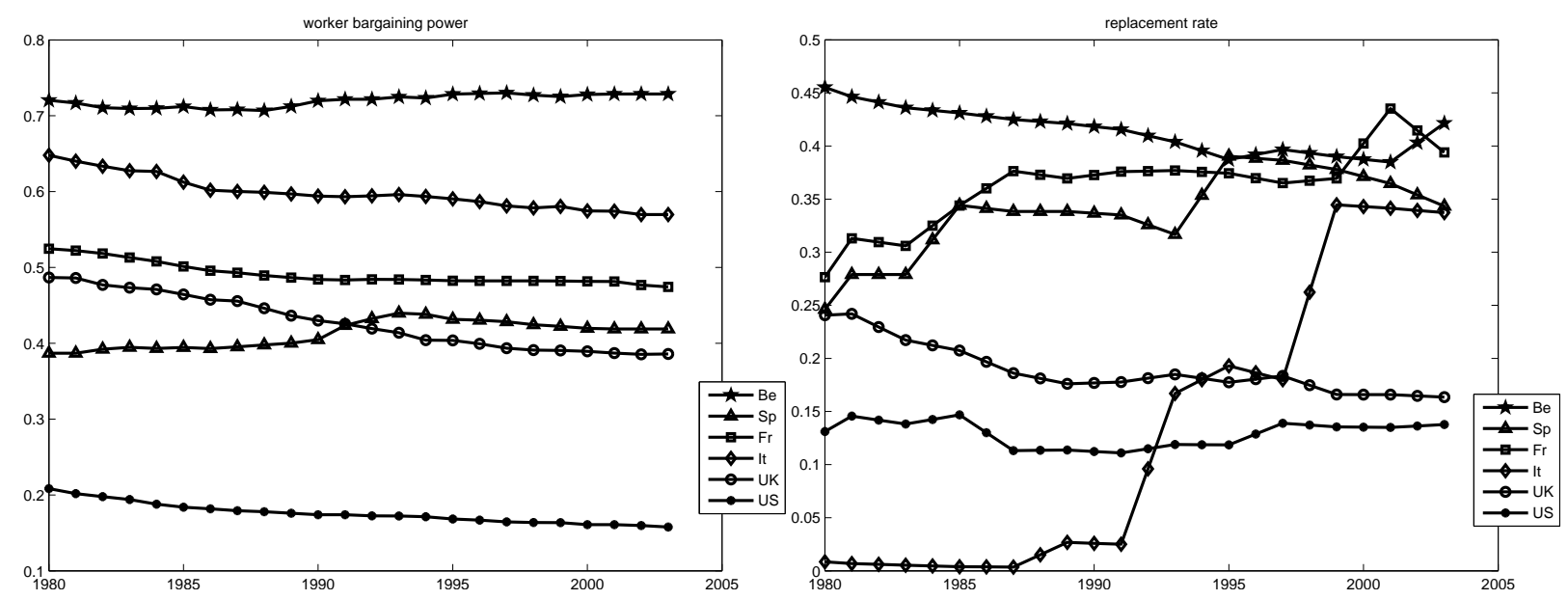

Table 5: Unemployment duration and the job destruction rate.

\begin{tabular}{l|cccccc}
\hline \hline Country & Belgium & Spain & France & Italy & United Kingdom & United States \\
\hline$\frac{1}{\Psi}^{*}$ (months) & 23 & 41 & 20 & 30 & 10 & 2.5 \\
$\mathrm{~s}(\%)$ & 5.95 & 6.15 & 6.10 & 5.75 & 10.40 & 30.48 \\
\hline \hline
\end{tabular}

*: Source: Blanchard and Portugal (2001). The authors construct monthly flows into unemployment as the average number of workers unemployed for less than one month, for the period 1985-1994, divided by the average labor force during the same period. The source of these data is the OECD duration database. Unemployment duration is constructed as the ratio of the average unemployment rate for the period 1985-1994 to the flow into unemployment. 
Figure 8: Unemployment duration
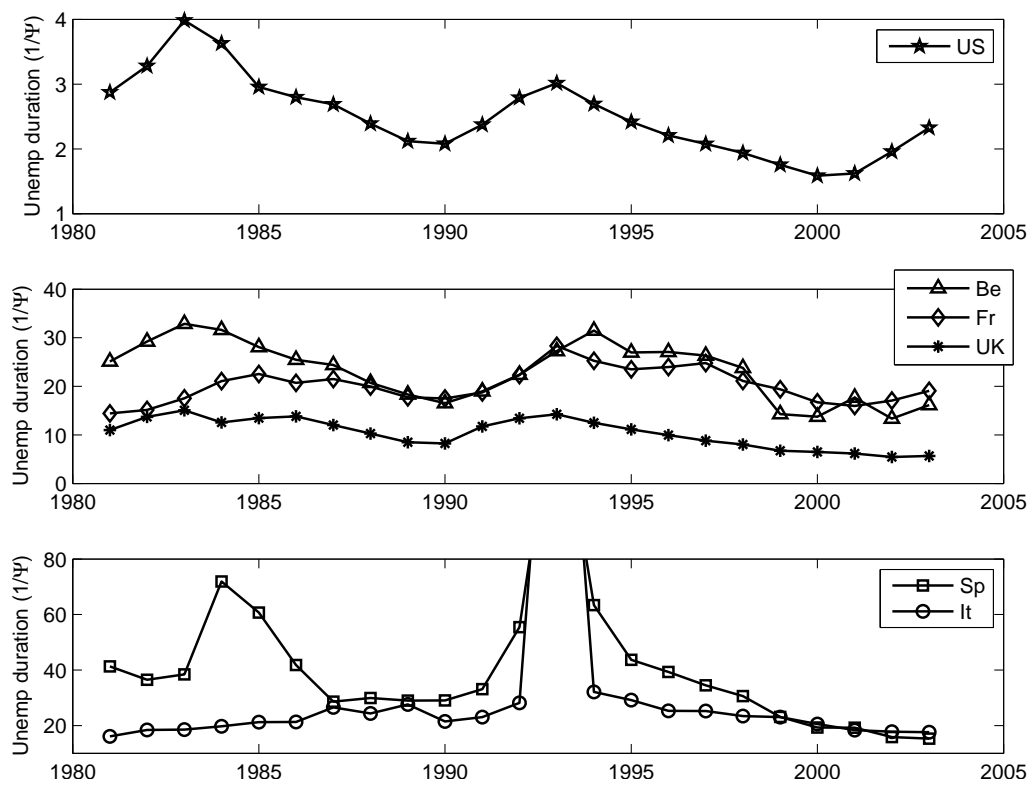

consumption $\left(\tau_{c}\right)$. These figures clearly show that there are two groups of countries: the first, with Belgium, France and Italy, where the tax wedge is high and the second, with Spain, the UK and the US, where the tax wedge is low. Figures show that these two groups of countries are the same if we focus on the labor tax or on the payroll tax. At the opposite, the consumption tax does not support this separation into two groups of countries.

\subsection{Empirical results}

In order to evaluate the impact of each deviation from the two neo-classical growth models presented in sections 2.1 and 2.2, we propose the following decomposition. First, we introduce only search costs in the measure of the marginal return of employment. Hence, in this first step (and as long as taxation is null), our theory on hours worked by employee is the same than in the neo-classical growth model with divisible hours, whereas the deviation between our theory on employment allocation and the Hansen-Rogerson' one comes from the countryspecific dynamics of the labor market tightness. In a second step, our objective is to measure the impact of country-specific labor market institutions, to know: the separation rate, the bargaining power and the unemployment benefits. Once again, this does not change our theory on the hours worked allocation, but modifies both the marginal return of employment and the marginal cost of employment. Next, we introduce country-specific dynamics of taxes, which change the allocation of both hours worked per employee and employment. This allows us to measure the relative impact of taxes. Finally, in order to asses the global impact of the tax/benefit systems, we consider simultaneously both sources of heterogeneity: the labor 
Figure 9: Taxes
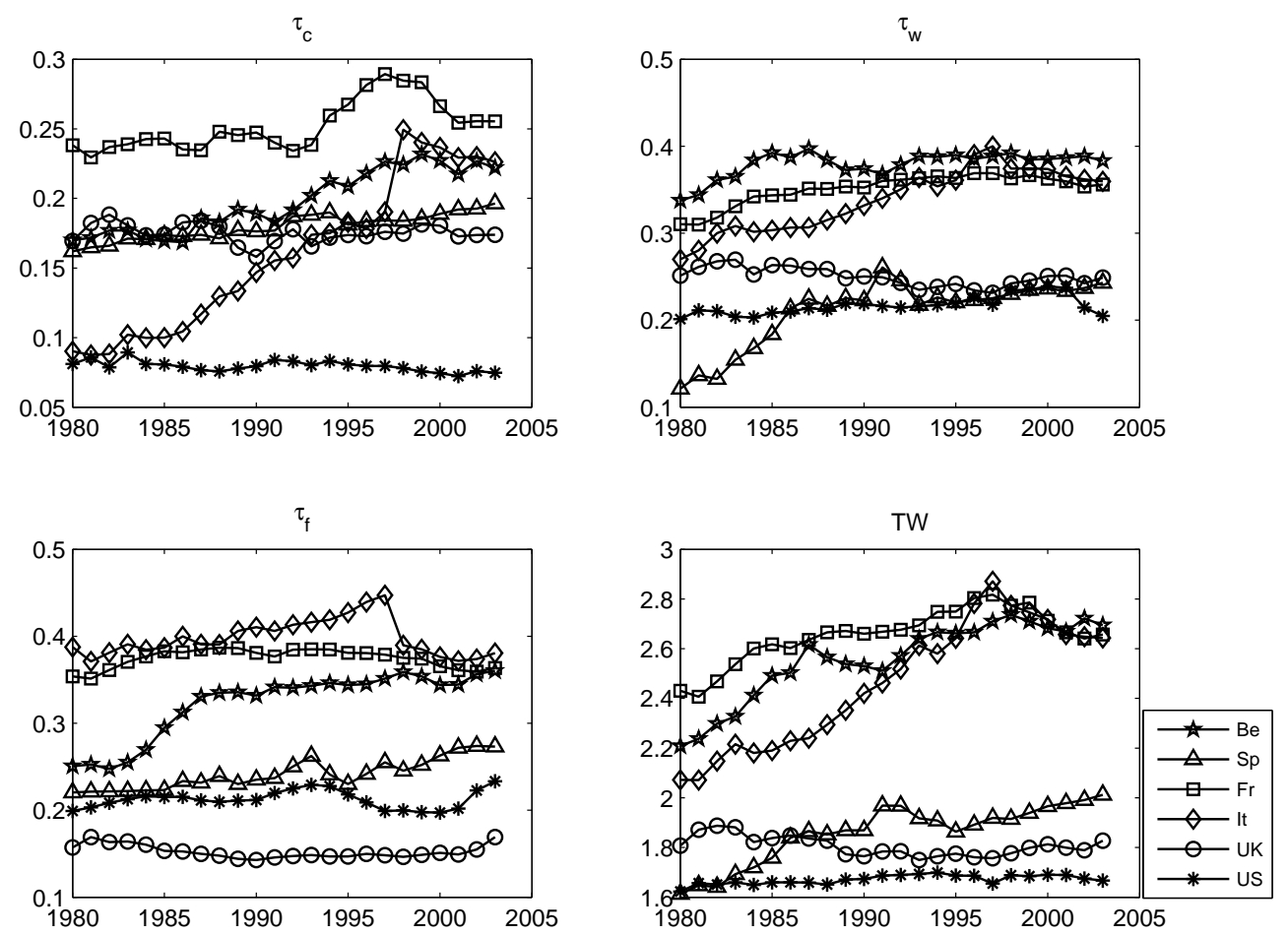

market institutions and taxation.

\subsubsection{A world with search costs}

Beyond the introduction of the labor market institutions such as bargaining and unemployment benefits, the matching model introduces search costs. The higher the unemployment rate, the higher is the probability to find a worker for a firm. Hence, in economies with high unemployment, search costs paid by firms are low. In order to evaluate the magnitude of the search costs, we set $T W=U B=0,1-\epsilon=0$ and $\omega>0$. Because our simple model does not introduce endogenous job separation, we only introduce a constant heterogeneity in the separation rate: $s=E_{i}\left[s_{i}\right]$, where $i$ denotes the country. Then we have:

$$
\begin{aligned}
M C N_{i, t} & =R W_{i, t}=\operatorname{MRS}(N / C)_{i, t} \\
M R N_{t} & =(1-\alpha) \frac{Y_{i, t}}{N_{i, t}}+(1-s) \frac{\omega}{\Phi_{i, t}}-\frac{C_{i, t}}{\beta C_{i, t-1}} \frac{\omega}{\Phi_{i, t-1}} \\
\Delta_{i, t}^{n} & =1-\frac{M C N_{i, t}}{M R N_{i, t}}
\end{aligned}
$$

These expressions explain why we get closer results than in the Hansen-Rogerson economy (see the appendix B where we report the results by country for the Hansen-Rogeson economy). The intuition is that agents face a similar employment lottery in both cases. Then, the $M C N$ is the same in the two types of economy. However, in the search economy 
of figure 10 the gap is lower because we take into account that search is a costly process. This is measured though an evaluation of the marginal rate of return of an employee $(M R N)$. In the US or in the UK, where the unemployment rate is significantly smaller, the search cost is higher for firms and then, the value of an employee is relatively higher than in the others countries. We observe the same phenomena for Spain at the end the sample period, where this country experienced a large decline of unemployment.

Figure 10: Employment in the model with search costs.

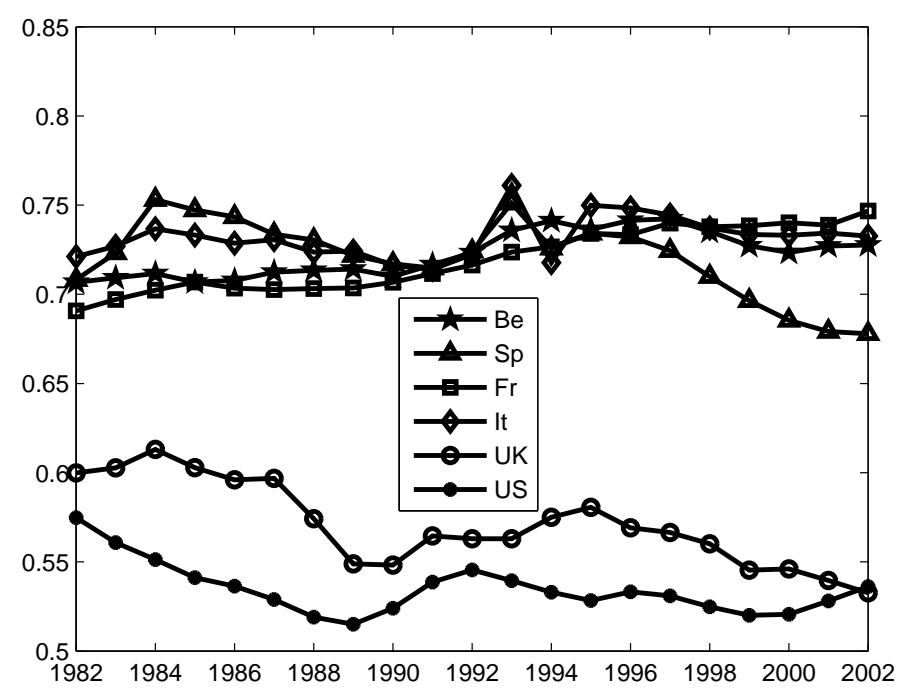

On the other side, the condition generating the number of hours worked in the nonwalrasian economy (figure 11) is the same than in the walrasian one, except that in the former the employment rate is not restricted to be equal to one. This expression does not introduce any labor market friction because we assume an efficient bargaining process over the hours worked. As discussed before, the evaluation of this model without taxes enlarges the gap between the marginal productivity of labor and its marginal cost.

\subsubsection{A world with country-specific institutions}

Is our theory able to explain the role of labor market institutions on the employment dynamics? In order to give a quantitative answer to this question, we introduce the country specific labor market indicators. Hence, in this configuration we set $T W_{i, t}=0,1-\epsilon_{i, t}>0$, $U B_{i, t}>0, s_{i}>0$ and $\omega>0$. This model allows us to evaluate the impact of the heterogeneity across countries of labor market institutions. As in the empirical literature (see e.g. Bassanini and Duval (2006)), we also take into account the country-specific dynamics of these labor market indicators (bargaining power and unemployment benefits). Then we 
Figure 11: Hours in the model with search costs

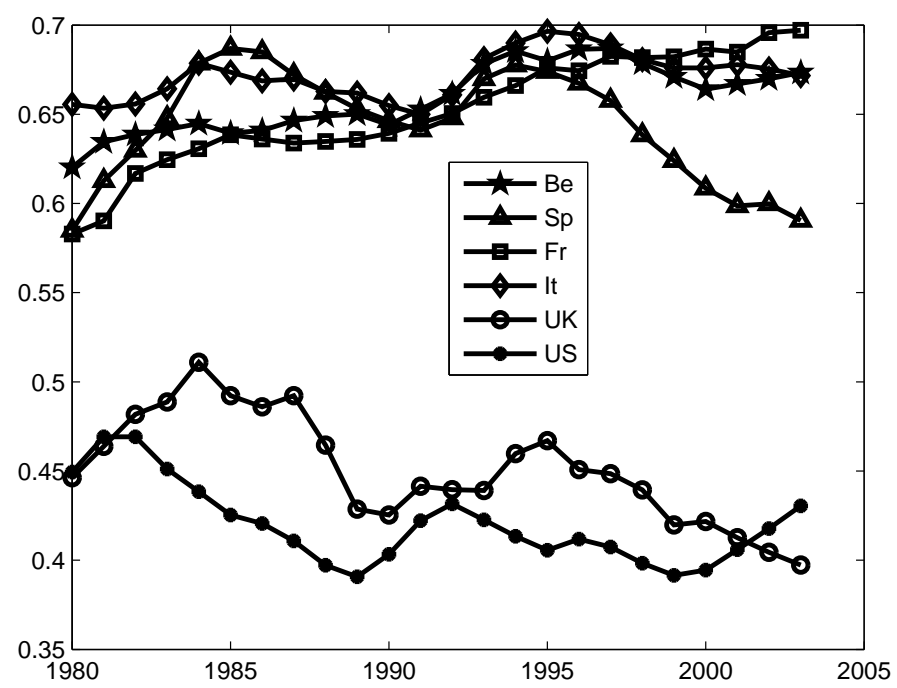

have:

$$
\begin{aligned}
R W_{i, t} & =M R S(N / C)_{i, t}+U B_{i, t} \\
B S_{i, t} & =(1-\alpha) \frac{Y_{i, t}}{N_{i, t}}+S C_{i, t} \\
M C N_{i, t} & =\left(1-\epsilon_{i, t}\right) B S_{i, t}+\epsilon_{i, t} R W_{i, t} \\
M R N_{i, t} & =(1-\alpha) \frac{Y_{i, t}}{N_{i, t}}+\left(1-s_{i}\right) \frac{\omega}{\Phi_{i, t}}-\frac{C_{i, t}}{\beta C_{i, t-1}} \frac{\omega}{\Phi_{i, t-1}} \\
\Delta_{i, t}^{n} & =1-\frac{M C N_{i, t}}{M R N_{i, t}}
\end{aligned}
$$

Since we do not introduce taxation, the heterogeneity comes only from the aggregates and from the labor market institutions. Results are reported in figure 12. The effect of the country-specific labor market indicators (worker's bargaining power, unemployment benefits and separation rates) is striking. Nevertheless, the results for the US economy are different from those for the European countries. Indeed, in the US, the observed labor market indicators are the lowest. Then, they have the smallest impact on the employment dynamics. At the opposite, when the labor indicators point to the existence of high real rigidities, the introduction of such variables in the theoretical model largely improves its fit. This is true for all European countries, included the UK. Indeed the labor market reforms in this last country have only a gradual impact on the employment dynamics after the 80 s.

This experience clearly shows that in all countries, the gaps are largely damped when we take into account the country-specific heterogeneity of the labor market indicators. This gives some empirical support to our theoretical approach: a matching model with wage bargaining accounts quite well for the employment dynamics if we introduce country-specific labor 
Figure 12: Employment with country-specific institutions (Taxes $=0)$

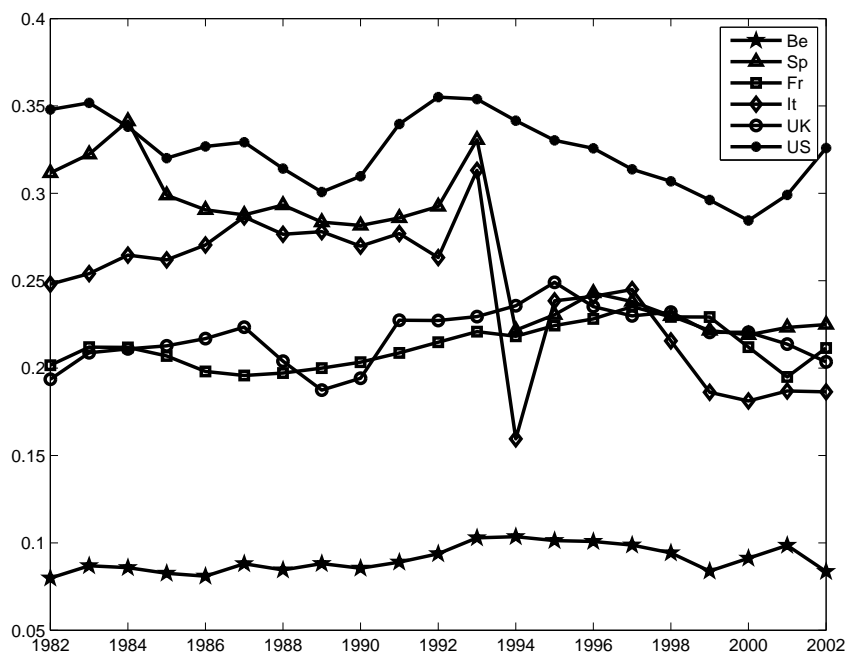

market indicators. On the other hand, this experience gives also a theoretical foundation for our regression results presented in table 4 .

\subsubsection{A world with country-specific taxation}

Which is the relative weight of taxes on the observed employment dynamics? In order to give a quantitative answer to this question, we set the labor market indicators to zero and we allow for positive taxation $\left(T W_{i, t}>0\right)$. In this case, workers have not bargaining power $\left(1-\epsilon_{i, t}=\right.$ $0)$ and, given that the unemployment benefits are equal to zero $\left(\rho_{i, t}=0\right)$, the reservation wage is just the marginal rate of substitution between employment and consumption, net of taxes. Finally, if the search is a costless process $(\omega=0)$, there are not intertemporal returns from labor. This configuration allows us to asses both the impact of the different tax systems across countries, and the relative weight of taxes with respect to the labor market institutions in shaping the employment behavior. Then we have:

$$
\begin{aligned}
M C N_{i, t} & =\left(1+T W_{i, t}\right) M R S(N / C)_{i, t} \\
M R N_{i, t} & =(1-\alpha) \frac{Y_{i, t}}{N_{i, t}}
\end{aligned}
$$

Results are shown in figure 13. The difference between this economy and the HansenRogerson's one, is that the number of hours worked per employees varies over time and across countries. Then, the measure of the reservation wage in this economy is coherent with the other evaluations of the matching model. By comparing this simulation and the results reported in appendix B, we measure the impact of the observed time-varying heterogeneity in hours worked on the extensive margin. For countries where the number of hours worked per employee is higher than the average of the sample (the calibration retained for the Hansen- 
Figure 13: Employment with country-specific taxation $(L M I=0)$

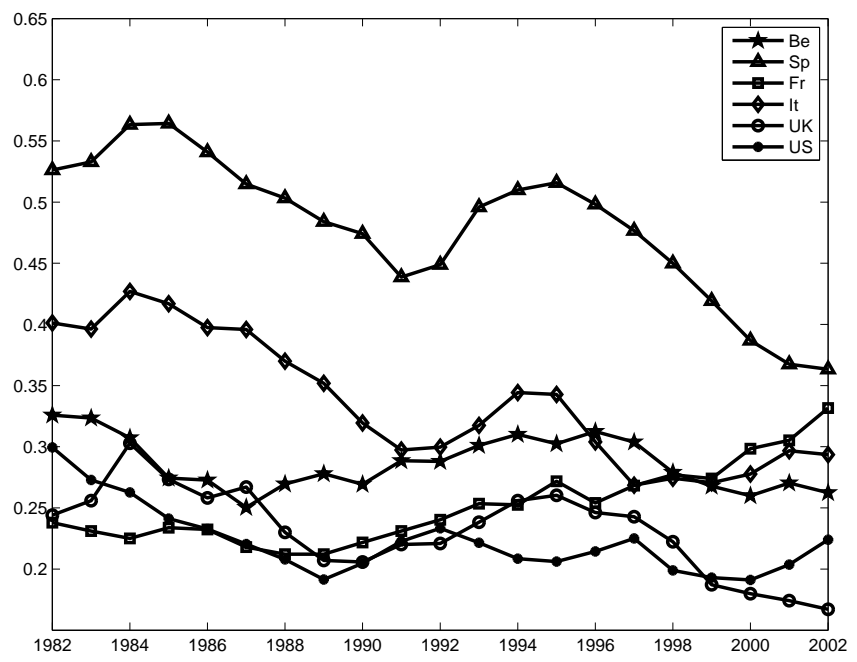

Rogerson economy), the reservation wage with flexible hours is bigger than its measure in the Hansen-Rogerson economy. Then, by taking into account the time-varying hours worked, we reduce the gap between theory and data for these countries (e.g. US and UK). The opposait is true for countries where the number of hours worked per employee is lower than the average.

By comparing the figures 13 and 12, we deduce that even if the effect of taxes is not negligible, the wedges still larger than in economy where only the heterogeneity of labor market institutions is taking into account.

\subsubsection{A world with country-specific taxation and institutions}

Finally, in this configuration we allow for both taxation and labor market institutions. That is, we set $T W_{i, t}>0,1-\epsilon_{i, t}>0, U B_{i, t}>0, s_{i}>0$ and $\omega>0$. The corresponding gap gives a measure of the under-utilization of employment implied by the tax/benefit system. Results are shown in figure 14. The improvement with respect to the two previous economies is in part due to the fact that, without taxes, the real wage is underestimated.

These results, concerning the relative contribution of taxes and labor market institution in the explanation of the employment dynamics, are well captured in figure 15. This figure shows the cross-country averages of the employment wedge for the various scenarios. In the top left panel we can asses the weight of unemployment. The gaps produced by the walrasian economy are very close to those produced by the search economy because the search costs are relatively small. The top right panel shows the marginal contribution of the labor market institutions whereas the bottom left panel shows the marginal contribution of taxes. Whereas the labor market institutions allow to divide the mean gap by 3 , taxes allow to divide the 
Figure 14: Employment with country-specific taxation and institutions

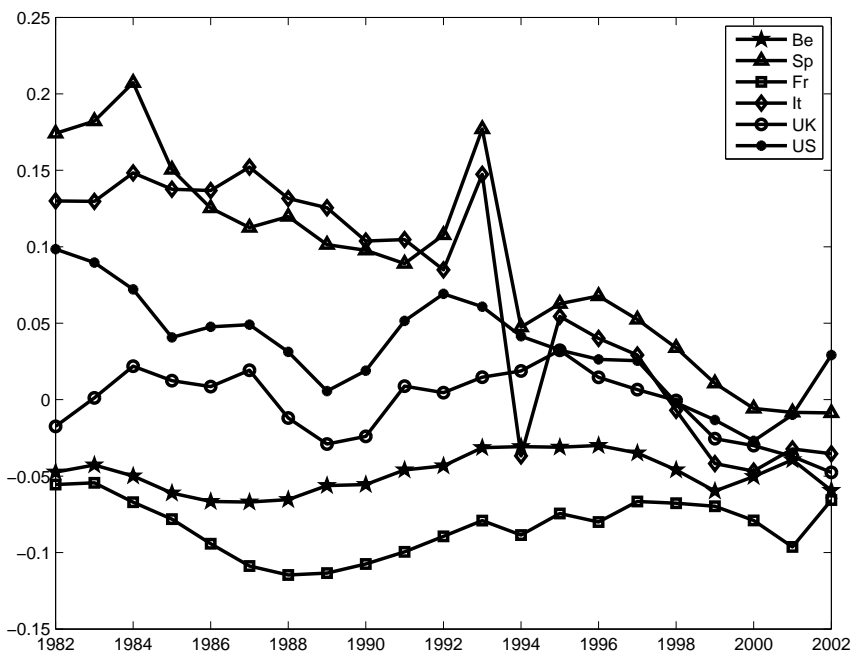

mean gap by 2 . The comparison of these two extreme cases enhances the preponderant role of the labor market institutions as determinant of the observed employment behavior. Finally, the bottom right panel shows the average wedges produced by our model when we integrate both sources of cross-country heterogeneity: taxation and labor market institutions. In this case the (average) gap between the model and data is largely damped and very close to zero.

Figure 15: Cross-country mean wedges (Employment)
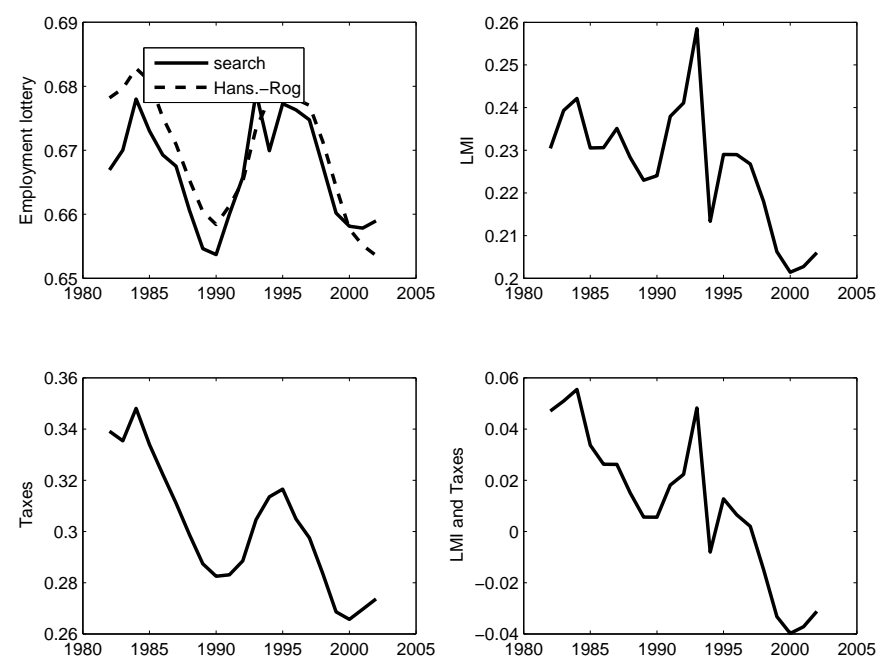

Finally, as expected, the gap between the theory and the data concerning the individual work effort diminishes because this setting captures the disincentive effect of taxes (figure $16)$.

$$
\Delta_{t}^{h}=1-\left(1+T W_{t}\right) \frac{M R S(H / C)_{t}}{M P H_{t}}
$$


Figure 16: Hours with country-specific taxation and institutions

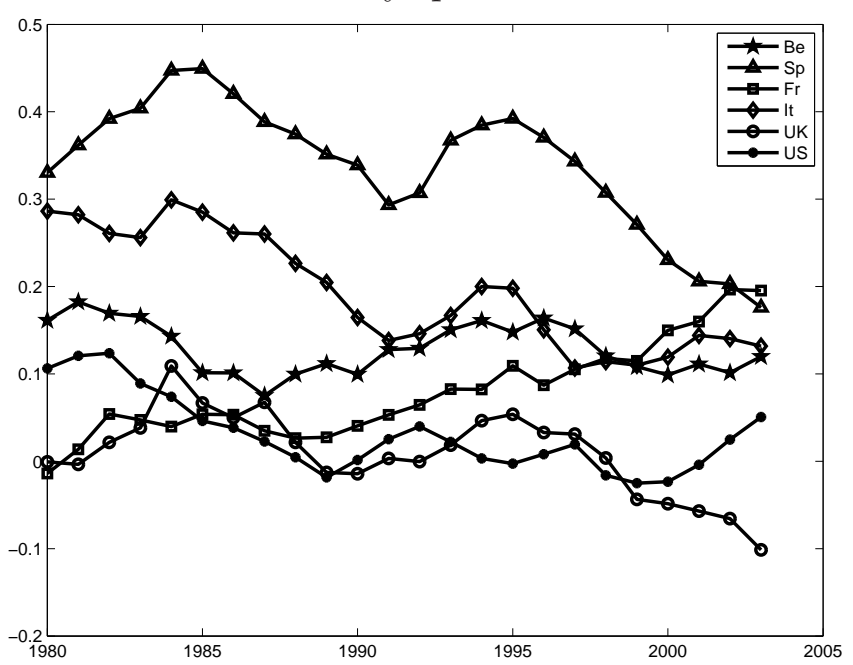

\section{Conclusion}

Aggregate hours of market work exhibit dramatic differences across industrialized countries. On the one hand, differences are large between Europe and the US. On the other hand, we observe large differences even among European countries. Moreover, since 1980 a notable feature of the data is that differences across countries in aggregate hours are due to quantitatively important differences along the extensive margin and the intensive margin.

The existing literature suggests that the main factors explaining the decline in the hours worked per employee differ from those explaining the decline in the employment rate: in the former case taxes play a prominent role (Prescott (2004), Rogerson (2006) and Ohanian, Raffo, and Rogerson (2006)), whereas labor market institutions, such as unions or unemployment benefits, explain the downturn in employment rates (Layard and Nickell (1991), Mortensen and Pissarides (1999), Blanchard and Wolfers (2000) or Ljungqvist and Sargent (2007)). In this paper, we show that all together contribute to the dynamics of the two margins of the total hours. We develop a model that includes the intensive and the extensive margins. The behavior of the two margins composing the aggregate hours is well accounted by our search model when it includes the observed heterogeneity across countries of both taxes and the labor market indicators (unemployment benefits and the bargaining power).

Relative to the walrasian economies, the general equilibrium matching model leads to new evaluations of both the marginal return of employment $(M R N)$ and the marginal cost of employment $(M C N)$. The labor market institutions lead to an increase in the $M C N$, through the introduction of both an additional value of leisure (the unemployment benefits) and a bargained surplus. Hence, we show that the shift across time of the labor market in- 
stitutions explains approximately $2 / 3$ of the dynamics of the employment rate. The increase of the tax wedge raises also the marginal cost of employment through the reservation wage. Through this channel, taxes explain about $1 / 3$ of the employment rate dynamics. Finally, we show that we need only taxes for accounting for the observed shift in the average hours worked per employee.

In addition, our quantitative experiences put in evidence that the US economy is closer to the walrasian model than the European economies, because frictions on the labor market are smaller. Finally, our results suggest than in all cases, the matching model performs better in the labor market accounting exercise.

\section{References}

Andolfatto, D. (1996): "Business cycle and labor market search," American Economic Review, 86(1), 112-132.

Bassanini, A., and R. Duval (2006): "Employment Patterns in OECD Countries: Reassesing the Role of Policies and Institutions," OECD Social, Employment and Migration Working Papers, 4(35).

Blanchard, O., and P. Diamond (1992): "The Flow Approach to Labor Markets," American Economic Review, 82(2), 501-515.

Blanchard, O., and P. Portugal (2001): "What Hides behind an Unemployment Rate: Comparing Portuguese and U.S. Labor Markets," American Economic Review, 91(1), $187-207$.

Blanchard, O., AND J. Wolfers (2000): "The role of shocks and institutions in the rise of european unemployment: the aggregate evidence," Economic Journal, 110, 1-33.

ChÉron, A., And F. LANGot (2004): "Labor market search and real business cycles: reconciling Nash bargaining with the real wage dynamics," Review of Economic Dynamics, 7, 476-493.

Daveri, F., AND G. TABellini (2000): "Unemployment, growth and taxation in industrial countries," Economic Policy, 15(30), 47-104.

FÈve, P., And F. LANGot (1996): "Unemployment and business cycle in a small open economy: GMM estimation and testing on French data," Journal of Economic Dynamics and Control, (20).

Hansen, G. (1985): "Indivisible Labor and the Business Cycles," Journal of Monetary Economics, 16, 309-327. 
Layard, R., And N. Nickell, S. AD Jackman (1991): "Unemployment, Macroeconomic Performance and the Labour Market," Oxford University Press.

LJungqvist, L., AND T. SARgent (2007): "Two Questions about European Unemployment," Forthcoming Econometrica.

McDaniel, C. (2007): "Average tax rates on consumption, investment, labor and capital in the OECD 1950-2003," Arizona State University, mimeo.

Mendoza, E., A. Razzin, And L. Tessar (1994): "Effective tax rates in macroeconomics: Cross-country estimates of tax rates on factor incomes and consumption," Journal of Monetary Economics, (34), 297-323.

Mortensen, D. T., and C. A. Pissarides (1999): "Unemployment Responses to 'SkillBiased' Technology Shocks: The Role of Labour Market Policy," Economic Journal, 109(455), 242-265.

Ohanian, L., A. Raffo, And R. Rogerson (2006): "Long-term changes in labor supply and taxes: evidence from OECD countries, 1956-2004," NBER Working Paper Series, (12786).

Prescott, E. (2004): "Why do Americans work so much more than Europeans?," Federal Reserve Bank of Minneapolis Quarterly Review, 28(1), 2-13.

Rogerson, R. (1988): "Indivisible labor, lotteries and equilibrium," Journal of Monetary Economics, 22(3), 501-515.

(2006): "Understanding differences in hours worked," Review of Economic Dynamics, (9), 365-409.

\section{A Data}

The sample is composed by Belgium, Spain, France, Italy, United Kingdom, United States. Depending on the availability of data, the analysis covers the 1980-2003 or the 1960-2003 period. Data on consumption, gross domestic product (GDP), employment, unemployment, population, wages and salaries, compensation of employees, the deflator of consumption and the defator of GDP (base year 2000) are from the OECD. ${ }^{7}$

Series for hours worked are from the Groningen Growth and Development Centre and the Conference Board, ${ }^{8}$ whereas the mesures of institutional variables are taken from the Bassanini and Duval (2006) database. The Bassanini et.al.'s collection of labor market variables covers a large period (1970-2003 or 1982-2003) and mostly rely on indicators provided by the

\footnotetext{
${ }^{7}$ OECD Statistics, beta 1.0: http://stats.oecd.org/wbos/default.aspx

${ }^{8}$ Total Economy Database, January 200\%: http://www.ggdc.net
} 
OECD. ${ }^{9}$ Finally, we take the series of the average tax rates on labor, capital and consumption from the McDaniel (2007)'s dataset, which covers 15 OECD countries for the period 1950-2003. ${ }^{10}$ The payroll tax is deduced from the ratio of the compensation of employees to the wage and salaries. Both mesures are taken from the OECD.

Job destruction. For each country $i$, the average rate of job destruction $s_{i}$ is computed such that the expected duration of unemployment $\left(E_{t}\left[1 / \Psi_{t}\right]\right)$ is equal to the mean unemployment duration reported in table 5 .

Job destruction in period $t\left(d_{i, t}\right)$ is defined as the sum of all net employment losses at establishments experiencing negative net employment gains between $t-1$ and $t$. Given the job destruction rate $s_{i}$ and actual data for employment, we compute the job destruction series as:

$$
d_{i, t}=s_{i} N_{i, t-1}
$$

The Job creation series are obtained from equation (30):

$$
M_{i, t}=N_{i, t}-N_{i, t-1}+d_{i, t}
$$

that is, the job creation in period $t$ is the sum of all net employment gains between $t-1$ and $t$. According with our model we compute series for the rate at which workers are matched with a vacant job as:

$$
\Psi_{t}=\frac{M_{t}}{U_{t-1}}
$$

where $U$ is the observed unemployment level. Then, using the definition of the matching function we derive the market tightness $(\theta)$ and the rate at which vacancies are matched with searching workers $(\Phi)$ :

$$
\begin{gathered}
\theta_{t}=\Psi_{t}^{\frac{1}{\psi}} \\
\Phi_{t}=\theta_{t}^{\psi-1}
\end{gathered}
$$

\section{B The Hansen-Rorgerson economy by country}

\footnotetext{
${ }^{9}$ The OECD Secretariat has constructed several indicators of policies and institutions that are comparable both across countries and over time. These indicators have been used in a wide range of macro-econometric studies to explore the labor market effects of policies and institutions.

${ }^{10}$ The McDaniel's tax estimates uses national account statistics as primary source and are in line with existing average tax rates calculated by Mendoza, Razzin, and Tessar (1994). In addition, these are the data used by Ohanian et.al. (2006).
} 
Figure 17: Hansen-Rogerson model ( $T W=0)$, 1980-2003

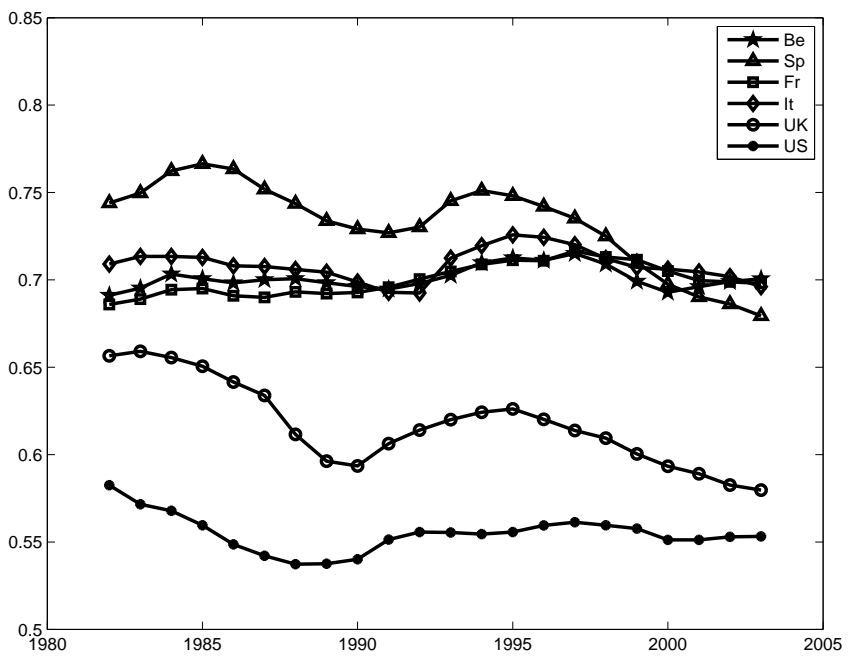

Figure 18: Hansen-Rogerson model $(T W>0), 1980-2003$

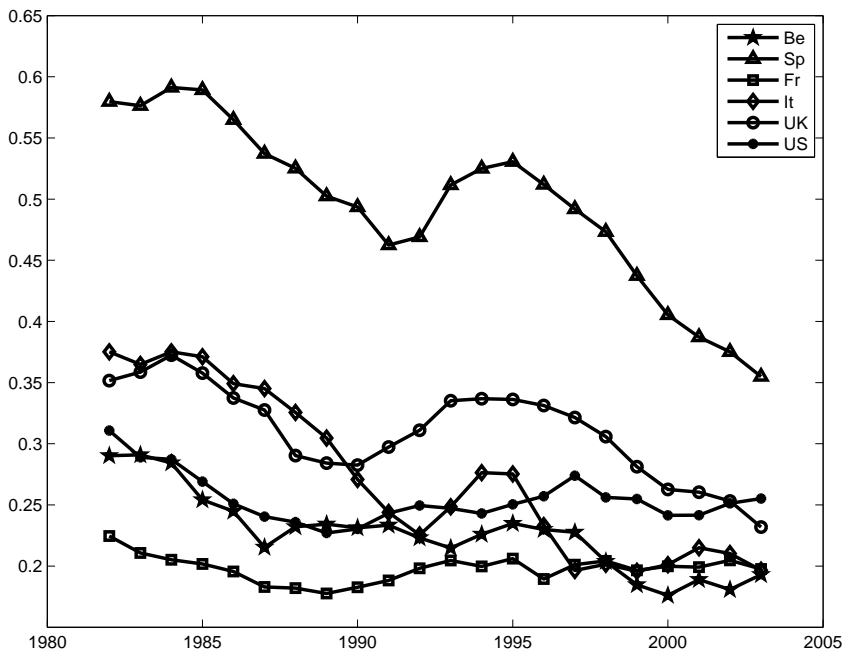

